\title{
Means restriction for the prevention of suicide by jumping (Review)
}

Okolie C, Wood S, Hawton K, Kandalama U, Glendenning AC, Dennis M, Price SF, Lloyd K, John A

Okolie C, Wood S, Hawton K, Kandalama U, Glendenning AC, Dennis M, Price SF, Lloyd K, John A.

Means restriction for the prevention of suicide by jumping.

Cochrane Database of Systematic Reviews 2020, Issue 2. Art. No.: CD013543.

DOI: 10.1002/14651858.CD013543.

www.cochranelibrary.com 
TABLE OF CONTENTS

HEADER 1

ABSTRACT

PLAIN LANGUAGE SUMMARY

SUMMARY OF FINDINGS

BACKGROUND

OBJECTIVES

METHODS

RESULTS

Figure 1.

Figure 2.

Figure 3.

Figure 4.

Figure 5.

Figure 6.

Figure 7.

DISCUSSION

AUTHORS' CONCLUSIONS

ACKNOWLEDGEMENTS

REFERENCES

CHARACTERISTICS OF STUDIES

ADDITIONAL TABLES

APPENDICES

CONTRIBUTIONS OF AUTHORS

DECLARATIONS OF INTEREST

SOURCES OF SUPPORT

DIFFERENCES BETWEEN PROTOCOL AND REVIEW 
[Intervention Review]

\section{Means restriction for the prevention of suicide by jumping}

Chukwudi Okolie1,2, Suzanne Wood ${ }^{3}$, Keith Hawton 4 , Udai Kandalama ${ }^{1}$, Alexander C Glendenning ${ }^{1}$, Michael Dennis ${ }^{1}$, Sian F Price ${ }^{5}$, Keith Lloyd ${ }^{1}$, Ann John 1,2

${ }^{1}$ Swansea University Medical School, Swansea, UK. ${ }^{2}$ Public Health Wales, Swansea, UK. ${ }^{3}$ Public Health Wales, Cardiff, UK. ${ }^{4}$ Centre for Suicide Research, University Department of Psychiatry, Warneford Hospital, Oxford, UK. ${ }^{5}$ Public Health Wales Observatory, Public Health Wales, Carmarthen, UK

Contact address: Ann John, Swansea University Medical School, Swansea, SA2 8PP, UK. a.john@swansea.ac.uk.

Editorial group: Cochrane Common Mental Disorders Group

Publication status and date: New, published in Issue 2, 2020.

Citation: Okolie C, Wood S, Hawton K, Kandalama U, Glendenning AC, Dennis M, Price SF, Lloyd K, John A. Means restriction for the prevention of suicide by jumping. Cochrane Database of Systematic Reviews 2020, Issue 2. Art. No.: CD013543. DOI: 10.1002/14651858.CD013543.

Copyright @ 2020 The Cochrane Collaboration. Published by John Wiley \& Sons, Ltd.

\section{A B S T R A C T}

\section{Background}

Jumping from a height is an uncommon but lethal means of suicide. Restricting access to means is an important universal or populationbased approach to suicide prevention with clear evidence of its effectiveness. However, the evidence with respect to means restriction for the prevention of suicide by jumping is not well established.

\section{Objectives}

To evaluate the effectiveness of interventions to restrict the availability of, or access to, means of suicide by jumping. These include the use of physical barriers, fencing or safety nets at frequently-used jumping sites, or restriction of access to these sites, such as by way of road closures.

\section{Search methods}

We searched the Cochrane Library, Embase, MEDLINE, PsycINFO, and Web of Science to May 2019. We conducted additional searches of the international trial registries including the World Health Organization International Clinical Trials Registry Platform (ICTRP) and ClinicalTrials.gov, to identify relevant unpublished and ongoing studies. We searched the reference lists of all included studies and relevant systematic reviews to identify additional studies and contacted authors and subject experts for information on unpublished or ongoing studies. We applied no restrictions on date, language or publication status to the searches. Two review authors independently assessed all citations from the searches and identified relevant titles and abstracts. Our main outcomes of interest were suicide, attempted suicide or self-harm, and cost-effectiveness of interventions.

\section{Selection criteria}

Eligible studies were randomised or quasi-randomised controlled trials, controlled intervention studies without randomisation, beforeand-after studies, or studies using interrupted time series designs, which evaluated interventions to restrict the availability of, or access to, means of suicide by jumping.

\section{Data collection and analysis}

Two review authors independently selected studies for inclusion and three review authors extracted study data. We pooled studies that evaluated similar interventions and outcomes using a random-effects meta-analysis, and we synthesised data from other studies in a narrative summary. We summarised the quality of the evidence included in this review using the GRADE approach. 


\section{Main results}

We included 14 studies in this review. Thirteen were before-and-after studies and one was a cost-effectiveness analysis. Three studies each took place in Switzerland and the USA, while two studies each were from the UK, Canada, New Zealand, and Australia respectively. The majority of studies (10/14) assessed jumping means restriction interventions delivered in isolation, half of which were at bridges. Due to the observational nature of included studies, none compared comparator interventions or control conditions.

During the pre- and postintervention period among the 13 before-and-after studies, a total of 742.3 suicides (5.5 suicides per year) occurred during the pre-intervention period ( 134.5 study years), while 70.6 suicides ( 0.8 suicides per year) occurred during the postintervention period (92.4 study years) - a 91\% reduction in suicides. A meta-analysis of all studies assessing jumping means restriction interventions (delivered in isolation or in combination with other interventions) showed a directionality of effect in favour of the interventions, as evidenced by a reduction in the number of suicides at intervention sites ( 12 studies; incidence rate ratio (IRR) $=0.09,95 \%$ confidence interval (Cl) 0.03 to $0.27 ; \mathrm{P}<0.001 ; \mathrm{I}^{2}=88.40 \%$ ). Similar findings were demonstrated for studies assessing jumping means restriction interventions delivered in isolation (9 studies; IRR $=0.05,95 \% \mathrm{Cl} 0.01$ to $0.16 ; \mathrm{P}<0.001 ; \mathrm{I}^{2}=73.67 \%$ ), studies assessing jumping means restriction interventions delivered in combination with other interventions ( 3 studies; IRR $=0.54,95 \% \mathrm{Cl} 0.31$ to $0.93 ; \mathrm{P}=0.03 ; \mathrm{I}=40.8 \%$ ), studies assessing the effectiveness of physical barriers ( 7 studies; IRR $=0.07,95 \% \mathrm{Cl} 0.02$ to $0.24 ; \mathrm{P}<0.001 ; \mathrm{I}^{2}=84.07 \%$ ), and studies assessing the effectiveness of safety nets ( 2 studies; $\mathrm{IRR}=0.09,95 \% \mathrm{Cl} 0.01$ to $1.30 ; \mathrm{P}=0.07 ; \mathrm{I}=29.3 \%$ ). Data on suicide attempts were limited and none of the studies used self-harm as an outcome. There was considerable heterogeneity between studies for the primary outcome (suicide) in the majority of the analyses except those relating to jumping means restriction delivered in combination with other interventions, and safety nets. Nevertheless, every study included in the forest plots showed the same directional effects in favour of jumping means restriction. Due to methodological limitations of the included studies, we rated the quality of the evidence from these studies as low.

A cost-effectiveness analysis suggested that the construction of a physical barrier on a bridge would be a highly cost-effective project in the long term as a result of overall reduced suicide mortality.

\section{Authors' conclusions}

The findings from this review suggest that jumping means restriction interventions are capable of reducing the frequency of suicides by jumping. However, due to methodological limitations of included studies, this finding is based on low-quality evidence. Therefore, further well-designed high-quality studies are required to further evaluate the effectiveness of these interventions, as well as other measures at jumping sites. In addition, further research is required to investigate the potential for suicide method substitution and displacement effects in populations exposed to interventions to prevent suicide by jumping.

\section{PLAIN LANGUAGE SUMMARY}

\section{Means restriction to prevent suicide by jumping}

\section{Why is this review important?}

Jumping from a height is an uncommon but lethal means of suicide. While there is evidence that restricting access to means of suicide is an effective approach for preventing suicides, the evidence for preventing suicide by jumping is not well established. This review therefore aimed to explore the impact restriction of access would have on suicide by jumping.

\section{Searching for evidence}

We searched several databases (the Cochrane Library, Embase, MEDLINE, PsycINFO, and Web of Science) to find studies that assessed the impact of restricting access to means of suicide by jumping. We searched the databases up until May 2019. We included studies that assessed jumping means restriction interventions delivered on their own, such as physical barriers, fencing or safety nets on bridges, or those delivered in combination with other suicide prevention interventions, such as crisis telephones and CCTV cameras. We also searched the reference lists of all included studies and relevant systematic reviews to identify additional studies and contacted authors to obtain missing information. Our main outcomes of interest were suicide, attempted suicide or self-harm and cost-effectiveness of interventions.

\section{Key results}

We found 14 relevant studies. Three studies each were from Switzerland and the USA, while two studies each were from the UK, Canada, New Zealand, and Australia respectively. The majority of studies had a before-and-after study design. Due to the observational nature of our included studies, none compared other interventions or control conditions. Jumping means restriction interventions delivered in isolation or in combination with other interventions were found to reduce the number of suicides by jumping. Data on suicide attempts were limited and no study reported self-harm. A cost-effectiveness analysis suggested that the construction of a physical barrier on a bridge would be cost-effective in the long term. The evidence for these assessments was of low quality because of weaknesses in study design and differences in findings between studies, therefore requiring the need for further high-quality studies. 
SUMMARY OF FINDINGS

Summary of findings for the main comparison. All means restriction interventions (delivered in isolation or in combination with other interventions) to restrict the availability of, or access to, means of suicide by jumping

All means restriction interventions (delivered in isolation or in combination with other interventions) to restrict the availability of, or access to, means of suicide by jumping

Patients or population: adults or children of all ethnicities

Setting: natural or man-made points of elevation

Intervention: interventions to restrict the availability of, or access to, means of suicide by jumping

Comparison: any other intervention or no intervention

\begin{tabular}{|c|c|c|c|c|c|c|}
\hline \multirow[t]{2}{*}{ Outcomes } & \multicolumn{2}{|c|}{ Absolute effects } & \multirow{2}{*}{$\begin{array}{l}\text { Relative effect } \\
(95 \% \mathrm{Cl})\end{array}$} & \multirow{2}{*}{$\begin{array}{l}\text { No of participants } \\
\text { (studies) }\end{array}$} & \multirow{2}{*}{$\begin{array}{l}\text { Quality of the } \\
\text { evidence } \\
\text { (GRADE) }\end{array}$} & \multirow[t]{2}{*}{ Comments } \\
\hline & $\begin{array}{l}\text { Before inter- } \\
\text { vention }\end{array}$ & $\begin{array}{l}\text { After inter- } \\
\text { vention }\end{array}$ & & & & \\
\hline $\begin{array}{l}\text { Suicide } \\
\text { (Observation period - pre-intervention: } 119.5 \text { years; } \\
\text { postintervention: } 92 \text { years) }\end{array}$ & 742.3 & 70.6 & $\begin{array}{l}\mathrm{IRR}=0.09,95 \% \mathrm{Cl} \\
0.03 \text { to } 0.27\end{array}$ & $\begin{array}{l}12 \text { before-and-after } \\
\text { studies }\end{array}$ & $\begin{array}{l}\oplus \oplus \oplus \ominus \\
\text { Lowa,b }\end{array}$ & \\
\hline Attempted suicide & - & - & - & - & - & \\
\hline Study withdrawal & - & - & - & - & - & \\
\hline Change in hospital admission rates & - & - & - & - & - & \\
\hline Cost-effectiveness of interventions & - & - & - & - & - & \\
\hline
\end{tabular}

Cl: confidence interval; IRR: incidence rate ratio

GRADE Working Group grades of evidence

High quality: further research is very unlikely to change our confidence in the estimate of effect.

Moderate quality: further research is likely to have an important impact on our confidence in the estimate of effect and may change the estimate.

Low quality: further research is very likely to have an important impact on our confidence in the estimate of effect and is likely to change the estimate.

Very low quality: we are very uncertain about the estimate.

a Upgraded by one level because of large magnitude of intervention effect

$b$ Downgraded by one level due to methodological limitations of the included studies and heterogeneity. 


\section{Summary of findings 2. Means restriction interventions delivered in isolation to restrict the availability of, or access to, means of suicide by jumping}

Means restriction interventions delivered in isolation to restrict the availability of, or access to, means of suicide by jumping

Patients or population: adults or children of all ethnicities

Setting: natural or man-made points of elevation

Intervention: interventions to restrict the availability of, or access to, means of suicide by jumping

Comparison: any other intervention or no intervention

\begin{tabular}{|c|c|c|c|c|c|c|}
\hline \multirow[t]{2}{*}{ Outcomes } & \multicolumn{2}{|c|}{ Absolute effects } & \multirow{2}{*}{$\begin{array}{l}\text { Relative effect } \\
(95 \% \mathrm{CI})\end{array}$} & \multirow{2}{*}{$\begin{array}{l}\text { No of partici- } \\
\text { pants } \\
\text { (studies) }\end{array}$} & \multirow{2}{*}{$\begin{array}{l}\text { Quality of the } \\
\text { evidence } \\
\text { (GRADE) }\end{array}$} & \multirow[t]{2}{*}{ Comments } \\
\hline & $\begin{array}{l}\text { Before inter- } \\
\text { vention }\end{array}$ & $\begin{array}{l}\text { After inter- } \\
\text { vention }\end{array}$ & & & & \\
\hline $\begin{array}{l}\text { Suicide } \\
\text { (Observation period - pre-intervention: } 89 \text { years; postin- } \\
\text { tervention } 78.5 \text { years) }\end{array}$ & 370.5 & 32.1 & $\begin{array}{l}\mathrm{IRR}=0.05,95 \% \mathrm{Cl} \\
0.01 \text { to } 0.16\end{array}$ & 9 studies & $\begin{array}{l}\oplus \oplus \ominus \ominus \\
\text { Lowa,b }\end{array}$ & \\
\hline Attempted suicide & - & - & - & - & - & \\
\hline Study withdrawal & - & - & - & - & - & \\
\hline Change in hospital admission rates & - & - & - & - & - & \\
\hline Cost-effectiveness of interventions & - & - & - & - & - & \\
\hline
\end{tabular}

Cl: confidence interval; IRR: incidence rate ratio

GRADE Working Group grades of evidence

High quality: further research is very unlikely to change our confidence in the estimate of effect.

Moderate quality: further research is likely to have an important impact on our confidence in the estimate of effect and may change the estimate.

Low quality: further research is very likely to have an important impact on our confidence in the estimate of effect and is likely to change the estimate.

Very low quality: we are very uncertain about the estimate.

a Upgraded by one level because of large magnitude of intervention effect

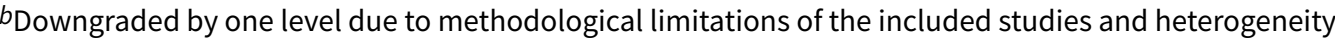


Summary of findings 3. Means restriction interventions delivered in combination with other interventions to restrict the availability of, or access to, means of suicide by jumping

\section{Means restriction interventions delivered in combination with other interventions to restrict the availability of, or access to, means of suicide by jumping}

Patients or population: adults or children of all ethnicities

Setting: natural or man-made points of elevation

Intervention: interventions to restrict the availability of, or access to, means of suicide by jumping

Comparison: any other intervention or no intervention

\begin{tabular}{|c|c|c|c|c|c|c|}
\hline \multirow[t]{2}{*}{ Outcomes } & \multicolumn{2}{|c|}{ Absolute effects } & \multirow{2}{*}{$\begin{array}{l}\text { Relative effect } \\
(95 \% \mathrm{CI})\end{array}$} & \multirow{2}{*}{$\begin{array}{l}\text { No of partici- } \\
\text { pants } \\
\text { (studies) }\end{array}$} & \multirow{2}{*}{$\begin{array}{l}\text { Quality of the } \\
\text { evidence } \\
\text { (GRADE) }\end{array}$} & \multirow[t]{2}{*}{ Comments } \\
\hline & $\begin{array}{l}\text { Before inter- } \\
\text { vention }\end{array}$ & $\begin{array}{l}\text { After inter- } \\
\text { vention }\end{array}$ & & & & \\
\hline $\begin{array}{l}\text { Suicide } \\
\text { (Observation period: pre-intervention } 30.5 \text { years; postin- } \\
\text { tervention } 13.5 \text { years) }\end{array}$ & 141.8 & 38.5 & $\begin{array}{l}\text { IRR } 0.54,95 \% \mathrm{Cl} 0.31 \\
\text { to } 0.93\end{array}$ & 3 studies & $\begin{array}{l}\oplus \oplus \ominus \ominus \\
\text { Lowa,b }\end{array}$ & \\
\hline Attempted suicide & - & - & - & - & - & \\
\hline Study withdrawal & - & - & - & - & - & \\
\hline Change in hospital admission rates & - & - & - & - & - & \\
\hline Cost-effectiveness of interventions & - & - & - & - & - & \\
\hline
\end{tabular}

Cl: confidence interval; IRR: incidence rate ratio

GRADE Working Group grades of evidence

High quality: further research is very unlikely to change our confidence in the estimate of effect.

Moderate quality: further research is likely to have an important impact on our confidence in the estimate of effect and may change the estimate.

Low quality: further research is very likely to have an important impact on our confidence in the estimate of effect and is likely to change the estimate.

Very low quality: we are very uncertain about the estimate.

a Upgraded by one level because of large magnitude of intervention effect

${ }^{b}$ Downgraded by one level due to methodological limitations of the included studies and heterogeneity. 
Summary of findings 4. Installation of barriers to restrict the availability of, or access to, means of suicide by jumping

\section{Barriers}

Patients or population: adults or children of all ethnicities

Setting: natural or man-made points of elevation

Intervention: interventions to restrict the availability of, or access to, means of suicide by jumping

Comparison: any other intervention or no intervention

\begin{tabular}{|c|c|c|c|c|c|c|}
\hline \multirow[t]{2}{*}{ Outcomes } & \multicolumn{2}{|c|}{ Absolute effects } & \multirow{2}{*}{$\begin{array}{l}\text { Relative ef- } \\
\text { fect } \\
(95 \% \mathrm{Cl})\end{array}$} & \multirow{2}{*}{$\begin{array}{l}\text { No of partici- } \\
\text { pants } \\
\text { (studies) }\end{array}$} & \multirow{2}{*}{$\begin{array}{l}\text { Quality of the } \\
\text { evidence } \\
\text { (GRADE) }\end{array}$} & \multirow[t]{2}{*}{ Comments } \\
\hline & $\begin{array}{l}\text { Before inter- } \\
\text { vention }\end{array}$ & $\begin{array}{l}\text { After inter- } \\
\text { vention }\end{array}$ & & & & \\
\hline $\begin{array}{l}\text { Suicide } \\
\text { (Observation period: pre-intervention } 81.5 \text { years; postintervention } \\
71.8 \text { years) }\end{array}$ & 359.9 & 34.7 & $\begin{array}{l}\text { IRR }=0.07 \\
95 \% \mathrm{Cl} 0.02 \text { to } \\
0.24\end{array}$ & 7 studies & $\begin{array}{l}\oplus \oplus \ominus \ominus \\
\text { Lowa,b }\end{array}$ & \\
\hline Attempted suicide & - & - & - & - & - & \\
\hline Study withdrawal & - & - & - & - & - & \\
\hline Change in hospital admission rates & - & - & - & - & - & \\
\hline $\begin{array}{l}\text { Cost-effectiveness of interventions (the study reviewed suicide } \\
\text { data from a bridge and surrounding areas over a } 70 \text {-year period, } \\
\text { and estimated reductions in mortality due to the barrier over a 20- } \\
\text { year period) }\end{array}$ & - & - & - & 1 study & $\begin{array}{l}\oplus \oplus \ominus \ominus \\
\text { Lowc }\end{array}$ & \\
\hline
\end{tabular}

CI: confidence interval; IRR: incidence rate ratio

GRADE Working Group grades of evidence

High quality: further research is very unlikely to change our confidence in the estimate of effect.

Moderate quality: further research is likely to have an important impact on our confidence in the estimate of effect and may change the estimate.

Low quality: further research is very likely to have an important impact on our confidence in the estimate of effect and is likely to change the estimate.

Very low quality: we are very uncertain about the estimate.

a Upgraded by one level because of large magnitude of intervention effect

$b$ Downgraded by one level due to methodological limitations of the included studies and heterogeneity.

cDowngraded by one level due to methodological limitations of the included study 


\section{Safety nets}

Patients or population: adults or children of all ethnicities

Setting: natural or man-made points of elevation

Intervention: interventions to restrict the availability of, or access to, means of suicide by jumping

Comparison: any other intervention or no intervention

\begin{tabular}{|c|c|c|c|c|c|c|}
\hline \multirow[t]{2}{*}{ Outcomes } & \multicolumn{2}{|c|}{ Absolute effects } & \multirow{2}{*}{$\begin{array}{l}\text { Relative effect } \\
(95 \% \mathrm{CI})\end{array}$} & \multirow{2}{*}{$\begin{array}{l}\text { No of partici- } \\
\text { pants } \\
\text { (studies) }\end{array}$} & \multirow{2}{*}{$\begin{array}{l}\text { Quality of the } \\
\text { evidence } \\
\text { (GRADE) }\end{array}$} & \multirow[t]{2}{*}{ Comments } \\
\hline & $\begin{array}{l}\text { Before inter- } \\
\text { vention }\end{array}$ & $\begin{array}{l}\text { After inter- } \\
\text { vention }\end{array}$ & & & & \\
\hline $\begin{array}{l}\text { Suicide } \\
\text { (Observation period: pre-intervention } 19.5 \text { years; postin- } \\
\text { tervention } 6.5 \text { years) }\end{array}$ & 22 & 1 & $\begin{array}{l}\mathrm{IRR}=0.09,95 \% \mathrm{Cl} \\
0.01 \text { to } 1.30\end{array}$ & 2 studies & $\begin{array}{l}\oplus \oplus \ominus \ominus \\
\text { Lowa,b }\end{array}$ & \\
\hline Attempted suicide & - & - & - & - & - & \\
\hline Study withdrawal & - & - & - & - & - & \\
\hline Change in hospital admission rates & - & - & - & - & - & \\
\hline Cost-effectiveness of interventions & - & - & - & - & - & \\
\hline
\end{tabular}

Cl: confidence interval; IRR: incidence rate ratio

GRADE Working Group grades of evidence

High quality: further research is very unlikely to change our confidence in the estimate of effect.

Moderate quality: further research is likely to have an important impact on our confidence in the estimate of effect and may change the estimate.

Low quality: further research is very likely to have an important impact on our confidence in the estimate of effect and is likely to change the estimate.

Very low quality: we are very uncertain about the estimate.

a Upgraded by one level because of large magnitude of intervention effect

$b$ Downgraded by one level due to methodological limitations of the included studies and heterogeneity. 


\section{B A C K G R O U N D}

\section{Description of the condition}

\section{Suicide rates}

Worldwide, suicide is recognised as a serious public health problem. Approximately 800,000 people die from suicide every year; a global mortality rate of 10.5 per 100,000 population (WHO 2019). However, it is suggested that global suicide figures could be underreported due to misclassification of suicides as accidents or other causes of death (WHO 2014). Suicide occurs throughout the lifespan and is the second-leading cause of death in 15 to 29 year olds worldwide, after road injury (WHO 2018). Globally, the majority of deaths by suicide occur in low-and-middle-income countries (79\%), however, high-income countries have the highest age-standardised suicide rates (11.5 per 100,000) (WHO 2019). Selfharm, which includes acts of self-poisoning or self-injury carried out by an individual irrespective of motivation (NICE 2011), is much more common than suicide and a significant cause of morbidity and mortality, including by suicide (Sinclair 2010; WHO 2014). In describing self-harm, we have followed the approach favoured in the UK and some other countries where all intentional self-harm (suicide attempt) is described/included in a single category, namely self-harm. (Hawton 2016).

\section{Risk factors/causes}

There are a variety of risk factors for suicide. These include mental disorders (particularly depression, anxiety, psychosis disorders and substance misuse), psychological, biological and genetic factors, exposure to role models and early-life adversity (Hawton 2009; Turecki 2016). A prior suicide attempt is the single most important risk factor for suicide in the general population (WHO 2014). Sex is also a factor, with higher rates of suicide reported in males (13.7 per $100,000)$ than in females $(7.5$ per 100,000) (WHO 2019). However, unlike suicide, self-harm usually occurs more commonly in females (Geulayov 2016; Hawton 2008). Whatever the background factors at the point when a person feels hopeless and suicidal, access to the means of suicide can be decisive (Hawton 2007). Availability of means can increase the likelihood of a suicide attempt, particularly where impulsive behaviour is a factor (Hawton 2007). The nature of the method chosen will influence the outcome (Yip 2012).

\section{Definitions}

A range of different terms are used for suicide and suicidal behaviour. In the context of this review, 'suicidal behaviour' refers to any form of intentional self-injurious or self-poisoning behaviour with known suicidal intent. 'Suicide' refers to selfinjurious or self-poisoning behaviour with a fatal outcome and known suicidal intent or where that intent was underdetermined. Self-harm includes acts of self-poisoning or self-injury irrespective of motivation.

\section{Means of suicide}

Despite differences between countries, worldwide three principal methods of suicide predominate - poisoning by ingestion of pesticides, hanging, and use of firearms.(WHO 2014). Suicide by jumping and other methods of poisoning (usually poisoning with drugs) are also significant methods. International variations in suicide methods suggest that the observed suicide pattern in many countries depends on the availability of the methods used (AjdacicGross 2008; Yip 2012). For example, suicide by jumping is the most common method of suicide in Hong Kong and other urban societies with extensive high-rise housing for both residential and work purposes (Wong 2014).

Jumping from a height, though an uncommon means of suicide, can be lethal (Elnour 2008). Most suicides by jumping occur from high-rise residential buildings (Beautrais 2007). Other common sites include cliffs, bridges, and terraces - some of which have gained reputations as sites for suicides (Beautrais 2007; Pirkis 2015). Prominent media coverage and style of reporting may contribute to imitation or contagion and thus enhance the status of these sites as places for suicide (Beautrais 2007; John 2017).

\section{Description of the intervention}

Restriction of availability or access to lethal methods of suicide (means restriction) is an important universal approach to suicide prevention. Universal prevention strategies are targeted at the general public or entire population groups. These strategies are designed to influence everyone and typically affect people whose suicide risk is otherwise undetected (Yip 2012). Means restriction is underpinned by the concept of intervention being available during acute periods of risk for suicidal behaviour; for example as might occur when a person with depression is exposed to an adverse life event. If access to means is restricted at this point, the chance of survival beyond the stage of acute risk increases. Evidence from research on near lethal suicide attempts supports the idea that, at least for a proportion of people, these acts may be an impulsive response and probably would not have occurred if the means had not been readily available (Hawton 2005). Means restriction is therefore applied to the population as a whole, where it typically affects vulnerable individuals, whose suicide risk may be undetected and who have not sought assistance in the midst of this crisis (Yip 2012).

It has been argued that restricting access to one method will lead to substitution with another. There is evidence, however, that restricting access to means during periods of acute risk can have an impact on an individual's likelihood of dying from suicide in the longer term. In the UK, an often used example is coal gas. From the late 1950 s to the early 1970 s, domestic gas supplies changed from toxic coal gas to non-toxic North Sea natural gas. After the Second World War, suicide rates in the UK had been increasing and carbon monoxide poisoning, using a gas oven, was the most common method. With the change to natural gas, the numbers of these deaths fell. Despite a slight increase in other methods, the net effect was a large reduction in suicide deaths (Kreitman 1976).

\section{How the intervention might work}

Suicides by jumping normally occur from man-made and natural points of elevation, such as high-rise buildings, bridges, cliffs and terraces. Means restriction interventions enacted at these sites work by either providing a physical obstruction to prevent jumping from these sites (e.g. physical barriers, fences, guard rails) or by restricting access to these sites (e.g., road closure, prevention of vehicular access). A range of studies have demonstrated that the construction of barriers and fencing at high-risk jumping sites, especially bridges, can lead to a reduction in the number of suicides by this method (Beautrais 2001; Bennewith 2007; Pelletier 2007; Pirkis 2013; Pirkis 2015). These interventions are oftentimes used in combination with other suicide prevention measures such as interventions aimed at increasing opportunities for help- 
seeking (e.g. crisis telephones), or those aimed at increasing the opportunity and capacity for human intervention (e.g. CCTV camera surveillance). Other measures such as responsible media reporting - including not reporting on method and context of a suicide (e.g. details of bridge), are also important for suicide prevention when used in combination with means restriction interventions.

\section{Why it is important to do this review}

Although there is clear evidence of the effectiveness of restricting access to lethal means as a suicide prevention measure, the evidence with respect to means restriction for the prevention of suicide by jumping is not well established. Previous reviews have focused on either suicide prevention at frequently-used locations (Cox 2013; Pirkis 2015), or general prevention of suicide by jumping (Beautrais 2007). A review published in 2013 assessed the effectiveness of structural interventions at frequentlyused locations (Pirkis 2013). This review did not follow strict Preferred Reporting Items for Systematic Reviews and MetaAnalyses (PRISMA) guidelines (Moher 2010), did not assess risk of bias of included studies, and had study searches conducted in July 2012. An updated systematic review specifically focused on means restriction interventions to prevent jumping suicides, using PRISMA guidelines, is therefore timely and necessary.

\section{O B JECTIVES}

To evaluate the effectiveness of interventions to restrict the availability of, or access to, means of suicide by jumping. These include the use of physical barriers, fencing or safety nets at frequently-used jumping sites, or restriction of access to these sites, such as by way of road closures.

\section{METHODS}

\section{Criteria for considering studies for this review}

\section{Types of studies}

We included primary research studies with the following study designs in this review: randomised controlled trials (RCTs), clusterRCTs, cross-over RCTs, and quasi-RCTs (trials in which allocation of participants to study arms is not truly random). Other study types eligible for inclusion included before-and-after studies, and studies using interrupted time series design. Due to the nature of this area of study, we anticipated that randomised trials would be unlikely, in which case we considered the best available evidence. We considered both published and unpublished studies. However, we excluded publications with no effectiveness data, such as editorials and case reports.

\section{Types of participants}

Adults or children of all ethnicities were eligible for inclusion in the review. Participants included individuals exhibiting suicidal behaviour. We also included studies with participants diagnosed with a mental disorder, as well as those in which a diagnosis had not been made prior to suicide or attempted suicide.

\section{Types of interventions}

\section{Experimental intervention}

We considered studies assessing the effectiveness of interventions to restrict the availability of, or access to, means of suicide by jumping. These include the use of physical barriers, fencing or safety nets at frequently-used jumping sites, or restriction of access to these sites, such as by way of road closures.

Some or all of these interventions could operate at multiple levels within the universal, selective, and indicated hierarchy as described below.

1. Universal interventions: targeted at the general public or whole populations.

2. Selective interventions: targeted at individuals or groups within a population at increased risk of suicidal behaviours

3. Indicated interventions: targeted at individuals with known suicidal behaviours.

The majority of jumping means restriction interventions operate at the universal level, however, where placements of barriers, nets or fences are in proximity to schools, psychiatric hospitals, and prisons, these interventions could operate at the indicated/ selective levels.

We excluded studies assessing the effectiveness of:

1. interventions aimed at educating professionals or the public about means of suicide;

2. interventions to restrict cognitive availability of means of suicide, for example the impact of media portrayals;

3. interventions aimed at improving recognition, screening for risk, treatment or the understanding of causes and risk factors of suicidal behaviour (including mental illness);

4. interventions solely aimed at increasing opportunities for helpseeking or third-party involvement (e.g. studies only assessing the effects of crisis telephones or CCTV cameras on bridges).

However, studies assessing means restriction interventions in combination with other suicide prevention measures such as interventions designed to increase help-seeking or third-party involvement or responsible media reporting, were included. We also excluded interventions on trains and railway networks as they are beyond the scope of this review, but will be included in a separate review, as part of our portfolio on means restriction (John 2018).

\section{Comparator intervention}

Comparator interventions or control conditions included any other intervention delivered in isolation e.g. crisis phones or CCTV on bridges, or no intervention. We also included studies with headto-head comparator interventions, e.g. signage on bridges versus structural changes.

\section{Types of outcome measures}

\section{Primary outcomes}

1. Suicide

2. Attempted suicide or self-harm

3. Study withdrawal

\section{Secondary outcomes}

1. Change in hospital admission rates for attempted suicide or selfharm

2. Cost-effectiveness of interventions 


\section{Timing of outcome assessment}

The effects of the interventions are expected to be immediate; however studies have shown that a short duration of follow-up (less than 2 years) following the introduction of a means restriction intervention may not be adequate to detect a change in the rate of suicides (Hawkins 2007; Hawton 2007). We therefore considered that for a study to be eligible for inclusion in a meta-analysis, it had to have a postintervention evaluation of at least two years followup for outcome assessment.

\section{Search methods for identification of studies}

\section{Electronic searches}

We searched the following electronic databases on 31 May 2019 (from the dates of inception).

1. The Cochrane Library (Issue 5 of 12, May 2019)

2. Ovid Embase (1974 onwards);

3. Ovid MEDLINE (1946 onwards);

4. Ovid PsycINFO (1806 onwards);

5. Web of Science (Science Citation Index (SCI) (1900 onwards) and Social Science Citation Index (SSCI) (1956 onwards).

The search strategy can be found in Appendix 1, Appendix 2, and Appendix 3.

We did not apply date, language, or publication status restrictions to these searches. In addition, we searched international trial registries via the WHO International Clinical Trials Registry Platform (ICTRP) (www.who.int/ictrp) and ClinicalTrials.gov (clinicaltrials.gov) to identify unpublished and ongoing studies.

\section{Searching other resources}

\section{Reference searching}

We searched the reference lists of all included studies and relevant papers known to our team, as well as the reference lists of relevant systematic reviews focusing on interventions to reduce suicide at jumping sites (Beautrais 2007; Cox 2013; Pirkis 2013; Pirkis 2015).

\section{Correspondence}

We contacted corresponding authors, chief investigators and subject experts for information on unpublished or ongoing studies or to request additional study data.

\section{Data collection and analysis}

\section{Selection of studies}

A two-stage screening process was undertaken by two review authors (CO and UK). Firstly, both review authors independently assessed all citations from the searches and identified relevant titles and abstracts. In the second stage, both reviewer authors independently assessed full texts of potentially eligible studies to identify studies to be included in the review. Disagreements at full text stage were resolved through discussion. Where disagreements could not be resolved, a third review author (AJ) was consulted.

\section{Data extraction and management}

Three review authors (CO, UK, SW) extracted data from all included studies using a modified version of the Cochrane Public Health Group Data Extraction and Assessment Template. This extraction tool was piloted on a random selection of four included studies prior to its use in the main review. Disagreements were resolved in the first instance through discussion, and where this failed, by referral to a fourth review author (AJ). Where necessary, authors of studies were contacted for clarification and for obtaining missing information or further unpublished data.

\section{Assessment of risk of bias in included studies}

Three review authors (CO, UK, SW) independently assessed risk of bias for each included study. We hypothesised that our included studies could consist of both randomised and nonrandomised studies, therefore the assessment criteria were based on Cochrane's 'Risk of bias' assessment tool (Higgins 2011), and the Cochrane ROBINS-I tool for non-randomised studies (Sterne 2016a). The ROBINS-I tool is currently available for cohort study designs but adaptations are being developed for other nonrandomised study types (Sterne 2016b).

For randomised trials, we made a judgement of 'low risk', 'unclear risk', or 'high risk' of bias for the following domains.

1. Random sequence generation.

2. Allocation concealment.

3. Blinding of participants, personnel and outcome assessors.

4. Incomplete outcome data.

5. Selective outcome reporting.

6. Other sources of bias.

For non-randomised studies, we made a judgement of 'low risk', 'moderate risk', 'serious risk', or 'critical risk' of bias for the following domains.

1. Confounding.

2. Selection bias.

3. Bias in classification of interventions.

4. Bias due to deviations from intended interventions.

5. Bias due to missing data.

6. Bias in measurement of outcomes.

7. Bias in selection of the reported result.

We critically appraised economic evaluations using the Cochrane recommended British Medical Journal Checklist for authors and peer reviewers of economic submissions (also known as the Drummond checklist; Drummond 1996). This checklist is grouped in 10 sections under three headings: study design; data collection; and analysis and interpretation of results. We made a judgement of 'yes', 'no', or 'not clear' for the following domains.

1. Study question.

2. Selection of alternatives.

3. Form of evaluation.

4. Effectiveness data.

5. Benefit measurement and valuation.

6. Costing.

7. Modelling.

8. Adjustments for timing of costs and benefits.

9. Allowance for uncertainty.

10.Presentation of results. 
Disagreements were resolved in the first instance by discussion and where this failed, by referral to a fourth review author (AJ).

\section{Measures of treatment effect}

\section{Continuous data}

Similar to previous reviews (Pirkis 2013; Pirkis 2015), we reported continuous data by calculating the pooled incidence rate ratio (IRR) using a random-effects Poisson regression analysis. Poisson regression was used as the outcome measure, IRR, follows a Poisson distribution, that is, the distribution describing independent, random events in a fixed time interval. In addition, this analysis estimates the change in suicide incidence from pre- to postintervention, while also assessing both baseline and betweenstudy variability in the intervention effect (Spittal 2015). To measure the effect of the interventions, we conducted six meta-analyses, including: (1) all studies assessing jumping means restriction interventions (delivered in isolation or in combination with other suicide prevention interventions); (2) studies assessing jumping means restriction interventions delivered in isolation; (3) studies assessing jumping means restriction interventions delivered in combination with other suicide prevention interventions; (4) studies assessing the effectiveness of barriers; (5) studies assessing the effectiveness of road closures that limited access to jumping sites; (6) studies assessing the effectiveness of safety nets.

\section{Unit of analysis issues}

We did not identify any cluster-RCTs, cross-over trials, or studies with multiple intervention/comparator groups in this review. Given the nature of the area of study, it is unlikely there will be any studies with multiple comparators or studies that are not observational in design.

\section{Dealing with missing data}

We did not conduct imputation of missing data because of the potential for introduction of bias. Where important data or information about the study design were missing, we contacted investigators or study sponsors in order to verify key study characteristics and obtain missing numerical outcome data, where possible.

\section{Assessment of heterogeneity}

We assessed heterogeneity between studies using the $\mathrm{I}^{2}$ statistic (Higgins 2011). The $\mathrm{I}^{2}$ statistic indicates the percentage of betweenstudy variation due to chance and can take any value from $0 \%$ to $100 \%$ (Higgins 2011). Thresholds for interpreting 12 are as follows: $0 \%$ to $40 \%$ - might not be important; $30 \%$ to $60 \%$ - may represent moderate heterogeneity; $50 \%$ to $90 \%$ - may represent substantial heterogeneity; $75 \%$ to $100 \%$ - considerable heterogeneity. The random-effects Poisson regression analysis employed for this review included an assessment of between-study heterogeneity (Spittal 2015). Where substantial heterogeneity was detected, possible causes were explored. Where not appropriate, studies were summarised in tables and narrative synthesis conducted.

\section{Assessment of reporting biases}

Reporting bias occurs when the decision to publish a research finding is influenced by the direction and significance of its results (Egger 1997). We planned to assess small study effects and potential publication bias using a funnel plot if a meta-analysis included results of at least 10 studies.

\section{Data synthesis}

We performed statistical analyses using statistical software $\mathrm{R}$ (version 3.4.3) (R Development Core Team 2017). Where more than one study examined the same intervention, and we judged the study populations and methods as being sufficiently similar, we conducted a meta-analysis using a random-effects Poisson regression model to provide an overall estimate of treatment effect. We reported continuous data by calculating the pooled IRR. Where we deemed meta-analysis inappropriate due to significant heterogeneity, we provided a narrative synthesis of results.

\section{Subgroup analysis and investigation of heterogeneity}

Planned subgroup analyses included:

1. history of self-harm versus no known history of self-harm;

2. diagnosis of mental disorder versus no known history of mental disorder.

\section{Sensitivity analysis}

For this review, we planned on analysing the effects of excluding studies that were methodologically different from other studies, studies judged to be at high risk of bias across one or more domain(s), and studies that contributed substantial levels of statistical heterogeneity. If the exclusion of these studies did not substantially alter the direction of effect or the precision of the effect estimates, then we included data from these studies in the analysis.

\section{'Summary of findings' tables}

We prepared 'Summary of findings' tables for the main outcome measure, suicide or attempted suicide. We used the GRADE system to assess the quality of evidence for each outcome (Schünemann 2011). Using the four standard GRADE levels of evidence (high, moderate, low and very low) we assigned evidence from RCTs an initial quality rating of high and evidence from observational studies an initial quality rating of low (Balshem 2011). We upgraded or downgraded these levels based on our judgements regarding risk of bias, precision, consistency, indirectness of study results, and publication bias. We interpreted the overall quality rating across studies in line with recommendations by Balshem and colleagues (Balshem 2011).

\section{RES U L T S}

\section{Description of studies}

\section{Results of the search}

We identified a total of 5409 citations from database searches. We identified 42 additional citations from other sources. After deduplication, the initial number of citations decreased to 3476 . Of these, we excluded 3422 citations after screening of titles and abstracts. We assessed 54 full-text articles for eligibility. We found 18 articles (representing 14 studies) to be eligible for inclusion in the review. Articles which relied on the same core data were grouped together and not discussed as individual studies. We included 12 studies in the meta-analysis overall. 
We excluded 36 articles (see Characteristics of excluded studies table). The results of all searches are presented in a PRISMA flow diagram (Figure 1; Moher 2010). 
Figure 1. Study flow diagram

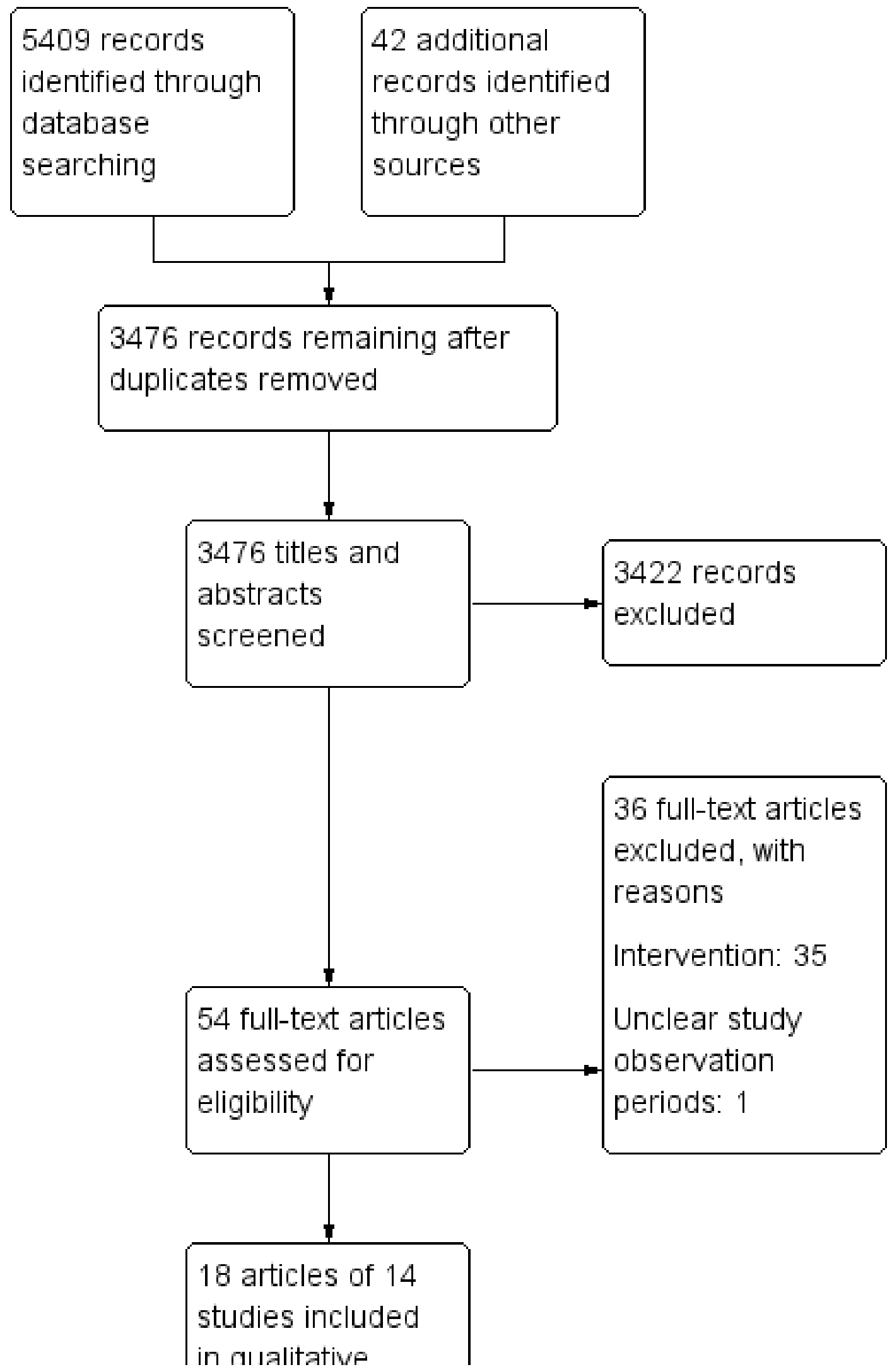


Figure 1. (Continued)

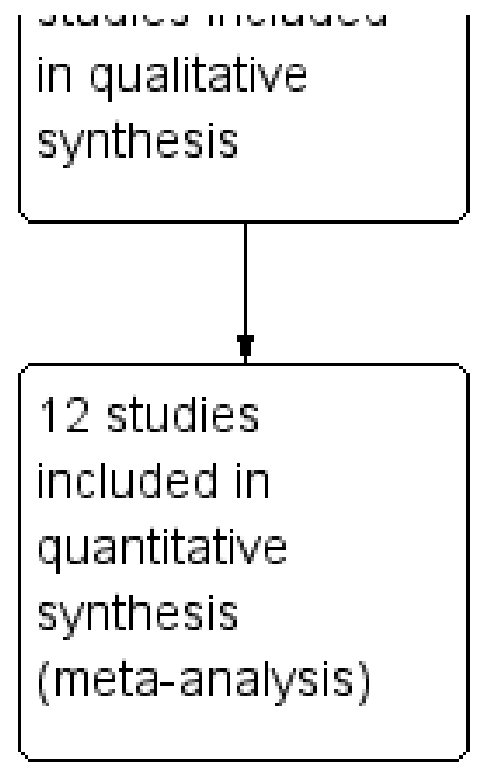

\section{Included studies}

Fourteen studies met all the inclusion criteria and were included in the review. The details of the individual studies are in the Characteristics of included studies table.

\section{Population}

Eight studies reported demographic data on the individuals who died by suicide by jumping from a height. All eight studies reported a male predominance of jumping suicides. The highest number of deaths was seen in men between the ages of 20 and 49 years. In three studies from four articles (Beautrais 2009; Isaac 2005; Skegg 2009), the majority of those who died by jumping had a comorbid psychiatric disorder or were under the care of mental health services at the time of the suicide.

\section{Design}

Of the 14 included studies, 13 were before-and-after studies. One study from two articles employed an A-B-A (reversal) design (Beautrais 2009). The only study not utilising a before-and-after study design was a cost-effectiveness analysis (Whitmer 2013). Due to the nature of this topic, none of the included studies employed a randomised controlled design as these would be difficult to implement.

\section{Setting}

Three studies each took place in Switzerland and the USA, while two studies each were from the UK, Canada, New Zealand, and Australia respectively. The majority of included studies evaluated interventions at bridges $(n=7)$, while the remaining studies evaluated interventions at headlands/ocean cliffs $(n=3)$, viaducts $(n=1)$, terraces $(n=1)$ and high-rise buildings $(n=1)$. Seven studies included details of the jump site such as the height of bridge/cliff drop $(n=7)$, or the type of surface underneath the bridge $(n=$ 4). Hemmer 2017 compared the effectiveness of a range of suicide prevention interventions at 15 jump sites (13 bridges, 1 terrace, and 1 multistorey car park).

\section{Interventions}

Ten studies assessed jumping means restriction interventions delivered in isolation. Six of these studies assessed the effectiveness of barriers installed on either bridges $(n=5)$ or viaducts $(n=1)$; two studies assessed the effectiveness of restricting road access to headlands/ocean cliffs; one study assessed the effectiveness of installing a safety net at a high terrace; and one study assessed the effectiveness of a guard rail installed at a high-rise hospital window. In both cases of road closure, the intervention was not primarily aimed at suicide prevention, but rather a coincidence of the need to restrict accessibility to the sites due to construction work and a Foot and Mouth outbreak respectively. Two studies from three articles assessed jumping means restriction interventions delivered in combination with other suicide prevention measures. In Lockley 2014, three types of interventions at an ocean cliff were studied collectively: barriers (means restriction), crisis telephones and signs (measures to increase opportunities for help-seeking), and CCTV cameras (measures to increase the opportunity for human intervention). Bennewith 2007 examined the effectiveness of barriers (means restriction) in combination with CCTV cameras and regular staff patrols (measures to increase the opportunity for human intervention) on a bridge. No study examined the effectiveness of media reporting in combination with jumping means restriction interventions. Hemmer 2017 compared the effectiveness of different suicide prevention interventions at 15 jumping sites. These interventions included barriers $(n=11)$ and safety nets $(n=4)$. In this study, six of the areas were secured by barriers and three of the areas secured by safety nets were additionally equipped with Help signs. This study also included an assessment of the extent of structural interventions, i.e. the effectiveness of structural interventions that secure an entire jump area (complete safety measures) or those that secure only a part of the jump area (incomplete safety measures). Three studies included details on the height of barriers/fences. Whitmer 2013 analysed the cost-effectiveness of a suicide barrier on a bridge. 


\section{Observation periods}

All of the included observational studies reported interventions that were assessed at two time points - before and after installation of the respective interventions. Pre-intervention periods ranged from four years to 22 years (median 10 years), while the postintervention periods ranged from 0.4 years to 22 years (median 5 years). The total pre- and postintervention periods were 134.5 years and 92.4 years, respectively (Table 1 ). In line with empirical evidence on the duration of time required for means restriction interventions to demonstrate impact on suicide rates (Hawkins 2007; Hawton 2007), we considered a postintervention evaluation period of at least two years for study eligibility in a meta-analysis. Only one study had a postintervention period of less than two years (Isaac 2005; Table 1). This study assessed the effectiveness of restricting road access to a jump site. We excluded data from this study from the meta-analysis but we have provided a narrative description. Hemmer 2017 compared the effectiveness of different suicide prevention interventions at 15 jump sites and provided individual pre- and postintervention observation period data for each location. The mean pre- and postintervention observation periods were therefore calculated for this study (14.9 years and 6.1 years respectively). The cost-effectiveness study did not report pre- and postintervention periods (Whitmer 2013), but instead reviewed suicides that occurred over a 70 -year period at one site and calculated what might be the cost per life saved over a 20-year period by the construction of a proposed bridge barrier.

\section{Outcomes}

\section{Primary outcome assessment}

Primary outcomes initially planned for evaluation in this review were suicide, attempted suicide, self-harm and study withdrawal rate.

\section{Suicide}

Thirteen of the included studies reported number of suicides per year in both the pre- and postintervention periods.

\section{Attempted suicide or self-harm}

Only two studies reported data on attempted suicide (Bennewith 2007; Skegg 2009). Whilst Skegg 2009 reported individual data on suicides and suicide attempts, data on suicides were not disaggregated from data on attempted suicide in Bennewith 2007. We therefore contacted the study authors for the individual data on suicide attempts. None of the studies used self-harm as an outcome.

\section{Study withdrawal}

Given the study design of all the included studies, study withdrawal rates were not reported in any of them. This outcome was therefore not assessed in the current review.

\section{Secondary outcome assessment}

Secondary outcome measures planned for evaluation in this review included change in hospital admission rates for attempted suicide or self-harm and cost-effectiveness of interventions.

\section{Change in hospital admission rates for attempted suicide or self-harm}

None of the included studies reported data on change in hospital admission rates for attempted suicide or self-harm. Suicide attempts were deemed more relevant to the current review.

\section{Cost-effectiveness of interventions}

Only one study reported cost-effectiveness data. This study evaluated the cost-effectiveness of a proposed barrier on a bridge (Whitmer 2013).

\section{Excluded studies}

We excluded 36 articles after reviewing full-texts (see Characteristics of excluded studies). Among these, 35 articles did not report interventions to restrict access to means of suicide by jumping, while one study reported data which was not interpretable as it did not report clearly defined observational periods.

\section{Ongoing studies}

We are not aware of any ongoing studies.

\section{Studies awaiting classification}

There were no studies awaiting classification.

\section{Risk of bias in included studies}

Since none of our included studies employed a randomised controlled design, we used the Cochrane ROBINS-I tool to assess risk of bias in the 13 included observational studies (Table 2; Table 3; Table 4; Table 5; Table 6; Table 7; Table 8; Table 9; Table 10; Table 11; Table 12; Table 13; Table 14). We assessed the methodological quality of the single cost-effectiveness analysis study using the 'Drummond checklist' for critically appraising economic evaluations (Table 15).

\section{Observational studies}

\section{Confounding}

Baseline confounding occurs when one or more prognostic variables also predicts the intervention received at baseline (Sterne 2016a). We only judged one study (from 2 articles) to be at low risk of bias due to confounding (Sinyor 2010). We judged the remaining included observational studies $(n=12)$ to be at moderate risk of bias due to confounding. In these studies, publicity (of the intervention/jump site) by media reports could have had a potentially confounding effect. This was not adjusted for in the analyses.

\section{Selection bias}

Selection bias occurs when exclusion of some eligible participants, or the initial follow-up time of some participants, or some outcome events, is related to both intervention and outcome (Sterne 2016a). Our included studies assessed interventions that were aimed at the general population; therefore all individuals who would have been eligible to take part in the study were included. We judged all 13 included observational studies to be at low risk of selection bias.

\section{Bias in classification of interventions}

Bias in classification of interventions occurs when there is either differential or non-differential misclassification of intervention 
status (Sterne 2016a). We judged 12 of the 13 included observational studies to be at low risk of bias in classification of interventions. We judged the remaining study to be at moderate risk of bias because electronic death records used in the study between 1960 and 1974 did not meet current data quality standards (Pelletier 2007), thereby leading to a potential underestimation of suicides during this time period.

\section{Bias due to deviations from intended interventions}

Bias due to deviations from intended interventions arises when there are systematic differences between experimental intervention and comparator groups in the care provided (Sterne 2016a). Since our included studies are observational in design with no comparator groups, assessment of this domain was based on the effect of starting and adhering to the intervention. We judged all 13 included observational studies to be at low risk of bias in this domain as there were no deviations from the intended interventions.

\section{Bias due to missing data}

Bias due to missing data arises when follow-up data are missing for individuals initially included in a study or when individuals with missing information about intervention status or other variables, are excluded (Sterne 2016a). We judged 7 of the 13 included observational studies to be at low risk of bias due to missing data. We judged the remaining six studies to be at moderate risk of bias, mainly due to the unavailability of suicide data at certain time periods.

\section{Bias in measurement of outcomes}

Bias in measurement of outcomes occurs when there is either differential or non-differential errors in measurement of outcome data (Sterne 2016a). We judged all 13 included observational studies to be at low risk of bias in this domain because the same methods were used to assess outcomes.

\section{Bias in selection of reported results}

Selective reporting arises when the reporting of results depends on the findings and prevents the estimate from being included in a meta-analysis (or other synthesis) (Sterne 2016a). We did not have access to study protocols for the studies included in this review, and as such it is difficult to assess this domain. We therefore gave a rating of 'unclear risk' for this domain to the 13 included observational studies.

\section{Cost-effectiveness analysis study}

For the evaluation of the cost-effectiveness analysis study (Table 15), we made a judgement of 'yes' for the following domains: study design; form of evaluation; benefit measurement and valuation; costing; adjustments for timing of costs and benefits; and presentation of results. We made a judgment of 'not clear' for effectiveness data, modelling, and allowance for uncertainty. The only domain with a judgement of 'no' was selection of alternatives, as this was not described.

\section{Effects of interventions}

See: Summary of findings for the main comparison All means restriction interventions (delivered in isolation or in combination with other interventions) to restrict the availability of, or access to, means of suicide by jumping; Summary of findings 2 Means restriction interventions delivered in isolation to restrict the availability of, or access to, means of suicide by jumping; Summary of findings 3 Means restriction interventions delivered in combination with other interventions to restrict the availability of, or access to, means of suicide by jumping; Summary of findings 4 Installation of barriers to restrict the availability of, or access to, means of suicide by jumping; Summary of findings $\mathbf{5}$ Installation of safety nets to restrict the availability of, or access to, means of suicide by jumping

\section{Primary outcomes}

\section{Suicide}

In the 13 included observational studies, a total of 742.3 suicides ( 5.5 suicides per year) occurred during the pre-intervention period (134.5 study years), while 70.6 suicides ( 0.8 suicides per year) occurred during the postintervention period (92.4 study years) - a $91 \%$ reduction in suicides (Table 1 ).

\section{a. All means restriction interventions (delivered in isolation or in combination with other interventions)}

A meta-analysis of 12 studies found a reduction in the number of suicides at sites where means restriction interventions (delivered in isolation or in combination with other interventions) were installed (incidence rate ratio (IRR) $=0.09,95 \%$ confidence interval $(\mathrm{Cl}) 0.03$ to $0.27 ; P<0.001$ ) (Figure 2). While the results of individual studies were all in the same direction of effect, there was considerable heterogeneity between studies as evidenced by $\mathrm{I}^{2}$ of $88.4 \%$. 
Figure 2. Forest plot of all studies assessing the effectiveness of jumping means restriction interventions (delivered in isolation or in combination with other interventions)

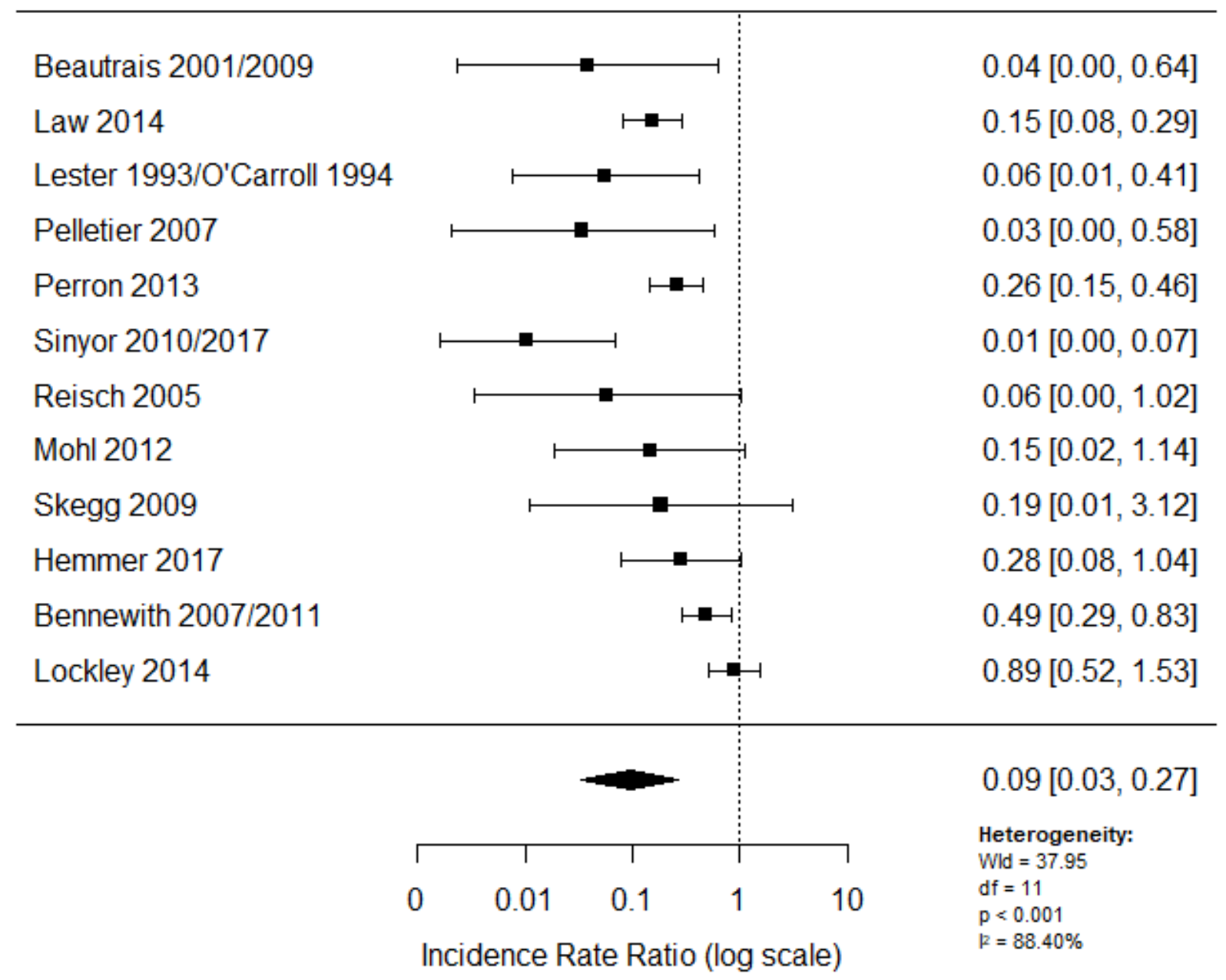

\section{b. Means restriction interventions delivered in isolation}

A meta-analysis of nine studies found a reduction in the number of suicides at sites where means restriction interventions were delivered in isolation (IRR $=0.05,95 \% \mathrm{Cl} 0.01$ to $0.16 ; \mathrm{P}<0.001$ )
(Figure 3). Similar to the meta-analysis of studies assessing the effectiveness of all means restriction interventions, there was evidence of considerable heterogeneity between studies $(12=$ $73.6 \%)$. 
Figure 3. Forest plot of studies assessing the effectiveness of jumping means restriction interventions delivered in isolation

\begin{tabular}{|c|c|c|c|}
\hline Beautrais 2001/2009 & $\longmapsto$ & & $0.04[0.00,0.64]$ \\
\hline Law 2014 & $\mapsto-1$ & & $0.15[0.08,0.29]$ \\
\hline Lester 1993/O'Carroll 1994 & $\longmapsto$ & & $0.06[0.01,0.41]$ \\
\hline Pelletier 2007 & $\longrightarrow$ & & $0.03[0.00,0.58]$ \\
\hline Perron 2013 & $\mapsto-1$ & & $0.26[0.15,0.46]$ \\
\hline Sinyor 2010/2017 & $\longmapsto$ & & $0.01[0.00,0.07]$ \\
\hline Reisch 2005 & $y^{2}$ & & $0.06[0.00,1.02]$ \\
\hline Mohl 2012 & & -1 & $0.15[0.02,1.14]$ \\
\hline Skegg 2009 & $\longmapsto$ & \begin{tabular}{l}
$\square$ \\
\hdashline
\end{tabular} & $0.19[0.01,3.12]$ \\
\hline & & & \multirow{4}{*}{$\begin{array}{l}0.05[0.01,0.16] \\
\text { Heterogeneity: } \\
\text { WId }=11.90 \\
d f=8 \\
p=0.156 \\
k=73.67 \%\end{array}$} \\
\hline & $T$ & $\neg$ & \\
\hline & 0.01 & 10 & \\
\hline \multicolumn{3}{|c|}{ Incidence Rate Ratio (log scale) } & \\
\hline
\end{tabular}

c. Means restriction interventions delivered in combination with other interventions

A meta-analysis of three studies found a reduction in the number of suicides at sites where means restriction interventions were delivered in combination with other interventions (IRR $=0.54,95 \%$ $\mathrm{Cl} 0.31$ to $0.93 ; \mathrm{P}=0.03$ ) (Figure 4). There was however, moderate heterogeneity between studies $\left(I^{2}=40.8 \%\right)$. 
Figure 4. Forest plot of studies assessing the effectiveness of jumping means restriction interventions delivered in combination with other interventions

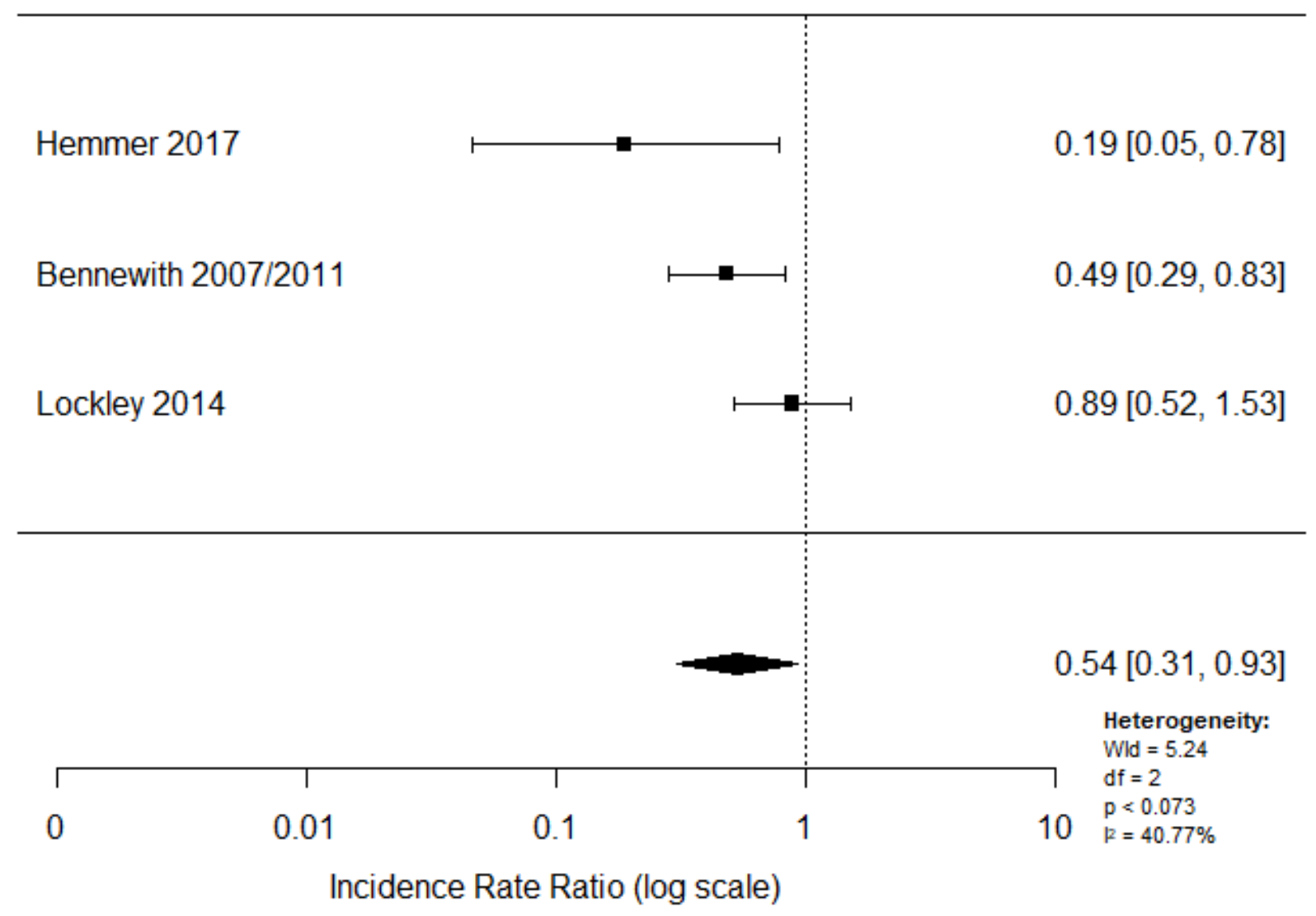

\section{d. Barriers}

A meta-analysis of seven studies found a reduction in the number of suicides at sites where physical barriers were installed (IRR $=0.07$,
$95 \% \mathrm{Cl} 0.02$ to $0.24 ; \mathrm{P}<0.001$ ) (Figure 5). There was considerable heterogeneity between studies $\left(I^{2}=84.1 \%\right)$. 


\section{Figure 5. Forest plot of studies assessing the effectiveness of barriers}

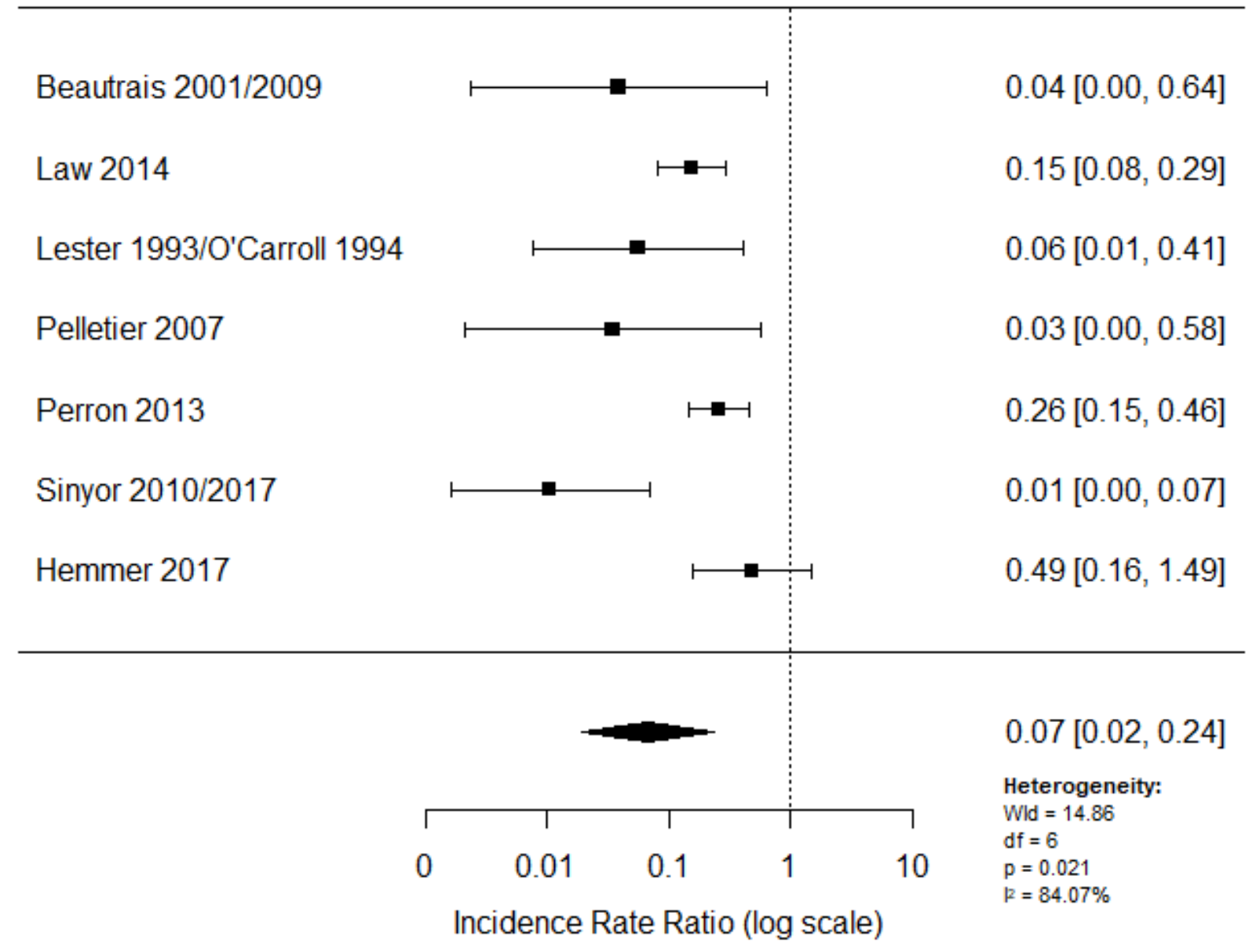

\section{e. Road closures}

Only one study assessing the effectiveness of restricting road access was eligible for inclusion (Skegg 2009), therefore we did not undertake a meta-analysis. This study reported a reduction in the number of suicides at the site of road closure (incident rate difference 1.3 deaths per year, $95 \% \mathrm{Cl} 0.60$ to 2.00 ). In this study, the intervention was not primarily aimed at suicide prevention, but rather a coincidence of the need to restrict accessibility to the site due to construction work.

\section{f. Safety nets}

A meta-analysis of two studies found a reduction in the number of suicides at sites where safety nets were installed, but this effect was not statistically significant (IRR $=0.09,95 \% \mathrm{Cl} 0.01$ to $1.30 ; \mathrm{P}=0.07$ ) (Figure 6). There was minimal heterogeneity between studies $\left(I^{2}=\right.$ $29.3 \%$ ) but this comparison included only two studies. 


\section{Figure 6. Forest plot of studies assessing the effectiveness of safety nets}

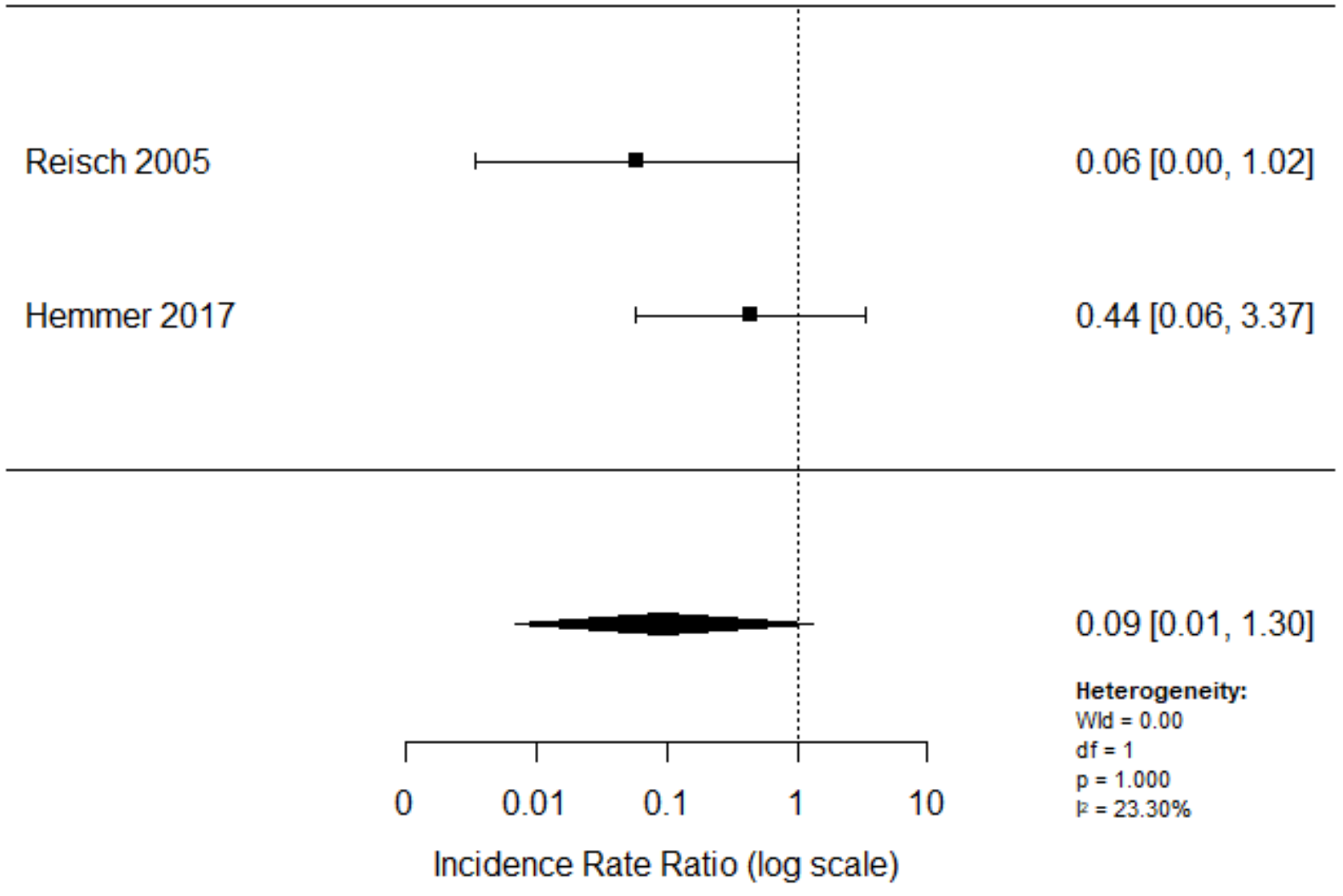

One study assessing the extent of structural interventions (Hemmer 2017), found that barriers and safety nets that secured the entire length of a jump area (complete measures) led to a reduction in suicides by $82.0 \%$ - from 184 suicides ( 1.6 per year) in the pre-intervention phase to 23 suicides ( 0.6 per year) in the postintervention phase, while safety measures that secured only a portion of the jump area (incomplete measures) led to a reduction in suicides by $44.8 \%$ - from 143 suicides (1.3 per year) in the pre-intervention phase to 15 suicides ( 0.3 per year) in the postintervention phase. Complete safety measures were significantly more effective at reducing jumping suicides than incomplete safety measures $(P=0.029)$.

\section{Attempted suicide or self-harm}

Only two studies assessed the impact of means restriction interventions on attempted suicide (Bennewith 2007; Skegg 2009). Bennewith 2007 evaluated the effectiveness of preventive barriers on a suspension bridge. The study reported that during the 10year study observation period, there was a total of 421 'fatal' and 'non-fatal' incidents where someone jumped or appeared to be at risk of jumping from the bridge of interest. Accordingly, we have interpreted 'fatal' incidents as suicides and 'non-fatal' incidents as reported in the study, as a combination of suicide attempts and incidents of people who were thought to be about to make attempts. There were 117 incidents (39 per year) recorded in the three years prior to installation of bridge barriers and 304 incidents (43 per year) in the seven years after installation. In this study, 
data on number of suicides were not disaggregated from data on suicide attempts, thereby making it difficult to fully assess the impact of this intervention on rates of attempted suicide. We contacted the study authors and were able to retrieve a complete individual dataset on fatal incidents (suicides) from the bridge during the study observation period (1996 to 2005). In the three years prior to installation of bridge barriers, there were 25 fatal and 92 non-fatal incidents, while in the seven years after installation there were 24 fatal and 280 non-fatal incidents at the bridge. Skegg 2009 evaluated the effectiveness of blocking off road access to a headland. This study presented separate data on suicides and suicide attempts. In the 10-year period before access to the headland was restricted, there were two suicide attempts at the site. In the two years after restriction of access, there were no attempts.

None of the included studies reported data on self-harm.

\section{Study withdrawal}

Study withdrawal was not reported in any of the included studies.

\section{Secondary outcomes}

Change in hospital admission rates for attempted suicide or selfharm

None of the included studies reported data on change in hospital admission rates for attempted suicide or self-harm.

\section{Cost-effectiveness of interventions}

Only one study presented data on the cost-effectiveness of interventions (Whitmer 2013). This study evaluated the costeffectiveness of a proposed suicide barrier on a bridge. The data from this study has been summarised in a narrative form. To estimate the cost-effectiveness of this barrier, the study authors reviewed suicide data from the bridge and surrounding areas over a 70-year period, and estimated reductions in mortality due to the barrier over a 20-year period. This study suggested that approximately 286 lives would be saved over a 20 -year period at an average cost per life of approximately USD 180,419. Furthermore, it was proposed that the barrier would generate considerable costsavings because other suicide prevention activities - such as suicide surveillance, negotiations, and recovery attempts by bridge patrols and other relevant authorities - might not be required.

\section{Subgroup analyses}

Planned subgroup analyses were not feasible. Most studies included in this review evaluated interventions aimed at the general population, and did not specify comorbidities or previous history of suicidal behaviour of individuals. We considered investigating the effects of geographical variation and structure type. However, with the available data we had, we did not believe these subgroup analyses would be useful. Of the 12 eligible included studies (two each from Switzerland, USA, Canada, New Zealand and Australia, and one from the UK), most evaluated interventions at bridges or bridge-like structures. Subgroup analysis was therefore not possible in this review but is planned for subsequent updates if feasible.

\section{Sensitivity analysis}

We conducted sensitivity analyses for the primary outcomes of suicide and attempted suicide. Where appropriate, studies that were methodologically different from other studies and those contributing to the marked heterogeneity in the analyses for the primary outcome were removed. Since we did not judge any studies to be at high risk of bias across one or more domains, we did not feel a sensitivity analysis was appropriate for this reason. We did not conduct sensitivity analyses for interventions combining multiple intervention types due to variations in these interventions. We therefore conducted a sensitivity analysis for the analysis of studies assessing the effectiveness of barriers (Figure 7). We removed one study from this analysis because we judged it to be methodologically different from the other studies (Hemmer 2017). This study evaluated interventions at multiple sites (in contrast to other studies that evaluated interventions at single sites) and reported individual pre- and postintervention data for each location. Mean pre- and postintervention were therefore calculated for this study. Analyses performed both with ( 7 studies; IRR $=0.07,95 \% \mathrm{Cl} 0.02$ to $0.24 ; \mathrm{P}<0.001)$ and without this study ( 6 studies; IRR $=0.05,95 \% \mathrm{Cl} 0.01$ to $0.19 ; \mathrm{P}<0.001$ ) did not substantially alter the direction of effect or the precision of the effect estimates. However, marked heterogeneity still persisted when pooling the estimates from these studies $\left(1^{2}=82.0 \%\right)$. 
Figure 7. Sensitivity analysis for the analysis of studies assessing the effectiveness of barriers

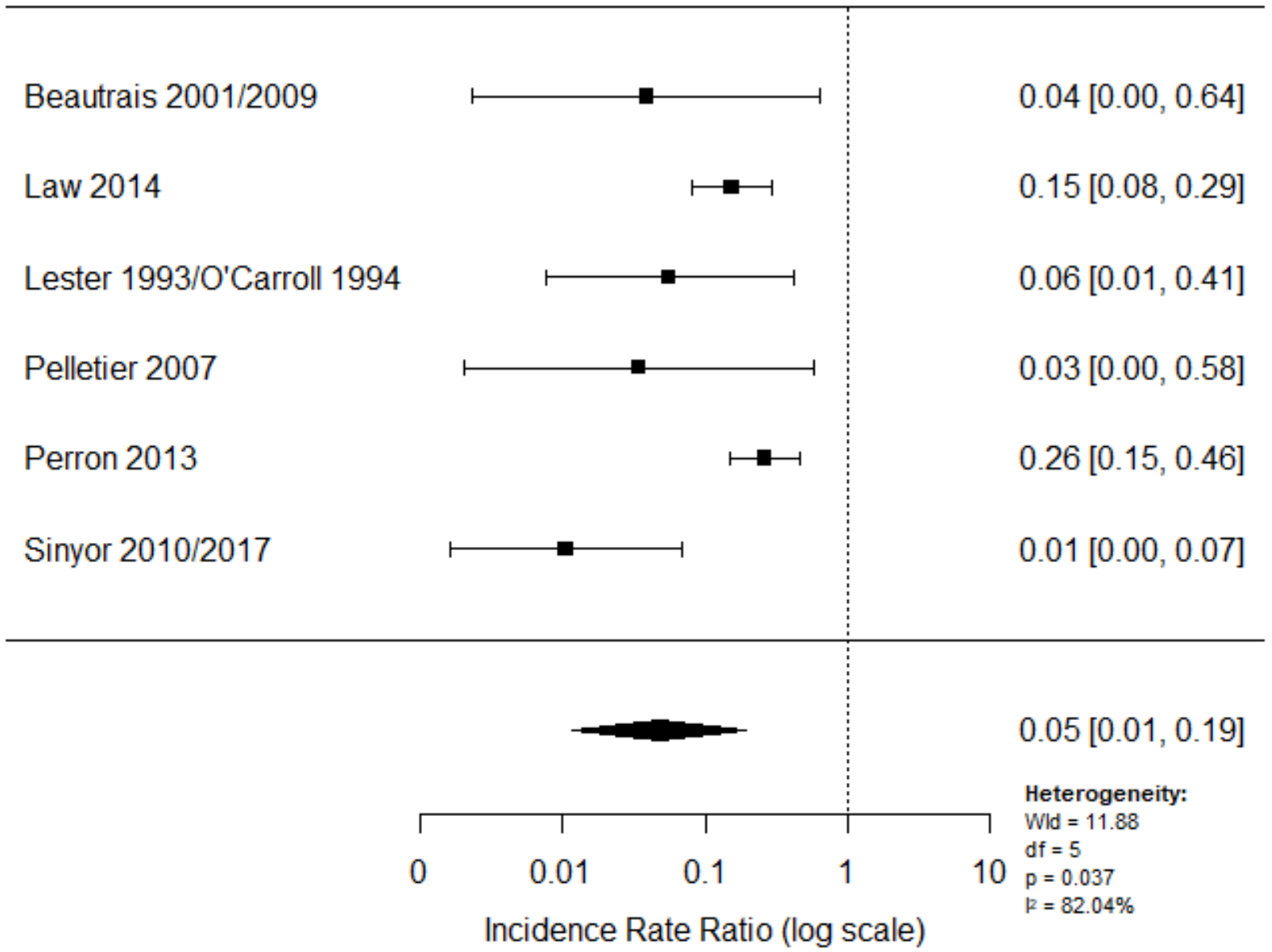

\section{DISCUSSION}

\section{Summary of main results}

The search identified 13 observational studies evaluating the effectiveness of various means restriction interventions for the prevention of suicide by jumping and one study evaluating the cost-effectiveness of a proposed barrier on a bridge. Ten studies assessed jumping means restriction interventions delivered in isolation: barriers $(n=6)$, blocking off road access to headlands/ ocean cliffs $(n=2)$, safety net $(n=1)$ and a guard rail $(n=1)$. In both cases of road closure, the intervention was not primarily aimed at suicide prevention, but rather a coincidence of the need to restrict accessibility to the sites due to construction work and a Foot and Mouth outbreak, respectively. Two studies assessed jumping means restriction in combination with other suicide prevention interventions, such as interventions aimed at increasing opportunities for help-seeking (crisis telephones, signage) and measures to increase the opportunity and capacity for human intervention (CCTV cameras, staff patrols). One study compared the effectiveness of different suicide prevention interventions at various frequently-used jumping locations. All 13 included observational studies reported data on the number of suicides pre- and postintervention. Due to the nature of the topic, most of the included studies were before-and-after studies. There was considerable heterogeneity of results between studies. 


\section{Primary outcomes}

\section{Suicide}

Overall, we found that restricting access to means can reduce the number of suicides by jumping. This finding was evident for the majority of jumping means restriction interventions, including those delivered in combination with other suicide prevention interventions. The findings from the meta-analyses assessing the effectiveness of all jumping means restrictions interventions; means restriction interventions delivered in isolation; means restriction interventions delivered in combination with other interventions; and barriers, showed significant reductions in the number of suicides at sites where the interventions were installed. However, we did detect heterogeneity across studies. Safety nets showed an effect in favour of the intervention; however, this effect was not significant. Measures that completely secured the entire length of jump sites were significantly more effective at reducing suicides than those that secured only a portion of the jump site.

\section{Attempted suicide or self-harm}

Suicide attempts, even though as important as deaths, are much more challenging to ascertain. Skegg 2009 found that no suicide attempts were made in the period following restriction of road access to a headland, compared to two attempts that were made in the period before restriction of access. However, the pre - and postobservation periods were 10 and two years, respectively. Bennewith 2007 reported 'fatal' and 'non-fatal' events at a bridge. The non-fatal events were a combination of suicide attempts and incidents of people who were thought to be about to make attempts. The study findings suggested an increase in non-fatal incidents after the installation of bridge barriers. The three-year pre-installation incidents were 92 , and the seven-year postinstallation incidents were 280 . Given the issues in defining these non-fatal incidents as suicide attempts, it is difficult to comment further on this finding with any certainty. None of the included studies used self-harm as an outcome.

We graded the quality of the evidence contributing to the assessment of the primary outcomes of suicide and attempted suicide as low, due to methodological limitations of the included studies and heterogeneity between studies.

\section{Secondary outcomes}

\section{Cost-effectiveness of interventions}

Based on one study (Whitmer 2013), a cost-effectiveness analysis suggested that the construction of a suicide barrier on a bridge would be a highly cost-effective project in the long term as a result of reduced suicide mortality by alternate methods. This study suggested that approximately 286 lives would be saved over a 20 -year period at an average cost per life of approximately USD 180,419 . It should be noted that the authors of this study adopted a conservative assumption that all suicides prevented by the barrier would attempt suicide with alternate methods. We graded the quality of the evidence contributing to the assessment of the primary outcome as low, due to methodological limitations of the study.

\section{Overall completeness and applicability of evidence}

In the course of this review, we conducted an extensive literature search using a wide range of search terms and databases, searched the reference lists of included studies and relevant systematic reviews, and contacted subject experts for information on unpublished or ongoing studies. Whilst possible, it is unlikely that we missed any relevant studies. We identified very few studies that assessed attempted suicides at frequently-used jumping locations. All of our included studies were conducted in highincome countries, and as such, our study findings may not be applicable to low- or middle-income countries, where financial and/or operational constraints may present challenges. One of the strengths of this review is that, in addition to establishing the effectiveness of means restriction interventions, we also sought to investigate their cost-effectiveness. However, we found only one economic study that matched our inclusion criteria. Further economic studies are required.

\section{Quality of the evidence}

We assessed the quality of the evidence included in this review as low using the GRADE criteria. This low rating was mainly due to methodological limitations of the included studies and considerable heterogeneity between studies. It should be noted that due to the nature of this topic, it would be highly impractical to undertake a randomised controlled trial (RCT) to evaluate the effectiveness of interventions. Observational studies, being more prone to bias, will therefore receive lower quality ratings.

\section{Potential biases in the review process}

In order to identify all relevant studies to be included in this review, we conducted an extensive search using a wide range of search terms and databases, searched the reference lists of included studies and relevant systematic reviews, and contacted subject experts for information on unpublished or ongoing studies. The electronic literature search did not include grey literature searching. It is possible that additional eligible studies may have been missed. Where applicable, we contacted study authors for missing outcome data. At least two review authors were involved in study selection, data extraction and quality assessment of included studies.

\section{Agreements and disagreements with other studies or reviews}

We did not identify any other systematic reviews focusing on means restriction for the prevention of suicide by jumping. However, we identified three systematic reviews (all conducted by members of the same team) that assessed interventions to reduce suicides at high-frequency locations - including jumping sites (Cox 2013; Pirkis 2013; Pirkis 2015), one evidence review by the National Institute for Health and Care Excellence (NICE) on reducing access to means (NICE 2018), and two narrative reviews on suicide by jumping highlighting research and prevention strategies (Beautrais 2007; Gunnell 1997). The systematic and evidence reviews differed from ours in three main ways: (a) the means of suicide were not restricted to jumping from a height, but also included other means such as carbon monoxide poisoning, collision with a train, and use of a firearm; (b) the interventions were not restricted to means restriction only but also included other interventions, such as those solely aimed at encouraging help-seeking or third-party intervention, and those restricting cognitive availability of means of suicide; and (c) the locations in these reviews were not restricted to jump sites and included sites beyond the scope of this review, such as railways and isolated woodland. Despite these differences, 
there was an overlap of 12 included studies ( 15 articles) between the most current of the systematic reviews (Pirkis 2015), and our review. Similarly, there was an overlap of 11 included studies (14 articles) between NICE 2018 and our review. All four reviews found relatively strong evidence of the effectiveness of means restriction in reducing suicide numbers, albeit that these studies were observational in nature so do not strictly meet the level in the hierarchy of evidence of RCTs. Similar to our review, there was evidence of heterogeneity across studies for the primary outcome of suicide or attempted suicide in both Pirkis' reviews and the NICE evidence review. In agreement with Pirkis, we believe that such heterogeneity is expected in this type of research due to the inherent differences within the studies, the jump sites, the types of interventions, and the differing demographics involved. This is in keeping with the argument regarding the inevitability of statistical heterogeneity in meta-analyses as a consequence of clinical and methodological diversity (Higgins 2011). We attempted to explore the heterogeneity by conducting a sensitivity analysis. This analysis did not substantially alter the direction of effect or the precision of the effect estimates, however heterogeneity still persisted. We also considered investigating the effects of geographical variation and structure type. However, with the available data we had, we did not believe these subgroup analyses would be useful.

None of the aforementioned reviews assessed attempted suicides at frequently-used jumping sites. Exclusion of this outcome in a study or review could underestimate the effect of an intervention and would therefore not provide a complete picture of the scale of the problem or prevention efforts. Furthermore, data on suicide method substitution was limited in all the reviews. The paucity of literature here means that we have to rely on evidence (which needs further exploration) that prevention in the acute suicidal episode reduces longer-term suicide risk.

Similar to the NICE evidence review, our review identified a study that made an assessment of the extent of structural interventions (Hemmer 2017). Barriers and safety nets that secured the entire jump area (complete measures) were found to be more effective at preventing suicides than structural interventions that secured only a part of the jump area (incomplete measures). The findings from this study suggest that, wherever possible, complete measures should be incorporated into the suicide prevention safeguarding of bridges.

Cost-effectiveness of interventions was not assessed in any of the aforementioned reviews.

\section{AUTHORS' CONCLUSIONS}

\section{Implications for practice}

The results from this review suggest that restricting access to means can reduce the number of suicides by jumping. This finding was evident even when means restriction was combined with other types of suicide prevention interventions. However, due to the current methodological limitations of included studies, the evidence in support of means restriction as a strategy for preventing suicide by jumping is of low quality. Despite this, across studies and intervention types, the directionality of effect favoured means restriction. The findings from this review add to the growing body of evidence in support of means restriction for suicide prevention, especially at frequently-used jumping sites. Bridge barriers were shown to be cost-effective (although based on a semi-hypothetical model), highlighting the importance of economic studies and the need for liaison with economists when designing such interventions.

\section{Implications for research}

The evidence for this review was limited in quality. Whilst, it may not be ethical or practical to conduct RCTs on interventions to reduce jumping, further well-designed high quality observational studies that address some of the biases highlighted in this review (confounding and bias due to missing data) are required to further evaluate the effectiveness of these interventions. Controlled before-and-after studies would provide a higher level of confidence in the findings around ruling out possible influence of secular trends and co-occurring interventions.

Few of the studies in this review included evaluation of the impact of interventions on attempted suicides at jumping sites. Focusing only on suicide incidents could underestimate the scale of the problem and overall impacts of interventions on suicidal behaviour. Further research incorporating data on suicide attempts from data sources such as hospital admissions/emergency department records, police and marine search and rescue records, is therefore required. Data on suicide method substitution was limited in this review. Evidence suggests that restricting access to means during periods of acute risk can have an impact on an individual's likelihood of dying from suicide in the longer term (Daigle 2005). For suicide by jumping, displacement to other jumping locations is probably more likely than a change in method (Perron 2013). Some of our included studies included displacement to other jumping sites as an outcome - with the majority showing minimal displacement. Further research is needed to investigate this potential effect in populations exposed to interventions to prevent suicide by jumping. Barriers were found to be effective at reducing the number of suicides at bridges, however only very few studies included details on the characteristics of barriers, such as the height, that could have contributed to its effectiveness. Further research is therefore required to explore these characteristics and to determine at what height a barrier should be to effectively prevent jumping suicides. Only one study assessing the effectiveness of road closures as a jumping means restriction intervention, was eligible for inclusion in this review. Futher robust research is therefore required to study this intervention method more closely. It was not feasible to undertake any of our planned subgroup analyses in this review. Suicidal behaviour is strongly associated with a history of self-harm or mental disorder. Future research investigating the presence of mental health diagnoses is therefore needed. In addition, further analysis investigating the potential effects of geographical variation and structural differences on means of suicide by jumping, is required. Similarly, factors that could impact on the lethality of jumping as a means of suicide, such as the height of structures and the type of underlying surfaces, require further study.

In a recent review on suicide prevention in older people (Okolie 2017), we identified studies that were more robust in that they examined overall rates of suicide by controlling for changes in population demography and comparing regionally, nationally and similar areas for trends over time. Equivalent analyses could be performed for implementation of barriers at key sites, exploring if there is a reduction in overall suicide and jumping suicides for a specific defined population, thereby investigating substitution of method. 
Finally, whilst installation of physical barriers has been the 'most extensively studied' intervention for preventing suicide by jumping, this may not necessarily mean it is the 'only effective' measure. Further studies evaluating the effectiveness of other measures at jumping sites are therefore required, for example interventions aimed at increasing opportunities for help-seeking (crisis telephones, signage) or human intervention (CCTV cameras, bridge staff patrols).

\section{A C K N OWLEDGEMENTS}

The review authors thank Cochrane Common Mental Disorders for providing support for this suite of reviews, and Swansea University Medical School and Public Health Wales for funding CO's post.

CRG Funding Acknowledgement: The National Institute for Health Research (NIHR) is the largest single funder of Cochrane Common Mental Disorders.

Disclaimer: The views and opinions expressed therein are those of the review authors and do not necessarily reflect those of the NIHR, the National Health Service (NHS), or the Department of Health and Social Care. 


\section{RE F E R E N C E S}

\section{References to studies included in this review}

Beautrais 2009 \{published data only\}

Beautrais AL. Effectiveness of barriers at suicide jumping sites: a case study. Australian and New Zealnd Journal of Psychiatry 2001;35(5):557-562.

* Beautrais AL, Gibb SJ, Fergusson DM, Horwood LJ, Larkin GL. Removing bridge barriers stimulates suicides: an unfortunate natural experiment. Australian and New Zealand Journal of Psychiatry 2009;43(6):495-7.

\section{Bennewith 2007 \{published data only\}}

Bennewith O, Nowers M, Gunnell D. Effect of barriers on the Clifton suspension bridge, England, on local patterns of suicide: implications for prevention. The British Journal of Psychiatry 2007;190(3):266-7.

* Bennewith O, Nowers M, Gunnell D. Suicidal behaviour and suicide from the Clifton Suspension Bridge, Bristol and surrounding area in the UK: 1994-2003. European Journal of Public Health 2011;21(2):204-8.

\section{Hemmer 2017 \{published data only\}}

Hemmer A, Meier P, Reisch T. Comparing different suicide prevention measures at bridges and buildings: lessons we have learned from a national survey in Switzerland. Plos One 2017;12:13.

\section{Isaac 2005 \{published data only\}}

Isaac M, Bennett J. Prevention of suicide by jumping: The impact of restriction of access at Beachy Head, Sussex during the foot and mouth crisis 2001. Public Health Medicine 2005;6:19-22.

\section{Law 2014 \{published data only\}}

Law CK, Sveticic J, De Leo D. Restricting access to a suicide hotspot does not shift the problem to another location. An experiment of two river bridges in Brisbane, Australia. Australian and New Zealand Journal of Public Health 2014;38:134-8.

\section{Lester 1993 \{published data only\}}

Lester D. Suicide from bridges in Washington, DC. Perceptual and motor skills 1993;77(2):534.

* O'Carroll PW, Silverman MM. Community suicide prevention: The effectiveness of bridge barriers. Suicide and LifeThreatening Behavior 1994;24(1):89-99.

\section{Lockley 2014 \{published data only\}}

Lockley A, Cheung YT, Cox G, Robinson J, Williamson M, Harris M, et al. Preventing suicide at suicide hotspots: a case study from Australia. Suicide and Life-Threatening Behavior 2014;44:392-407.

\section{Mohl 2012 \{published data only\}}

Mohl A, Stulz N, Martin A, Eigenmann F, Hepp U, Husler J, et al. The "Suicide Guard Rail": a minimal structural intervention in hospitals reduces suicide jumps. BMC Research Notes 2012;5:408.

\section{Pelletier 2007 \{published data only\}}

Pelletier AR. Preventing suicide by jumping: the effect of a bridge safety fence. Injury Prevention 2007;13(1):57-9.

Perron 2013 \{published data only\}

Perron S, Burrows S, Fournier M, Perron PA, Ouellet F. Installation of a bridge barrier as a suicide prevention strategy in Montreal, Quebec, Canada. American Journal of Public Health 2013;103:1235-9.

Reisch 2005 \{published data only\}

Reisch T, Michel K. Securing a suicide hot spot: Effects of a safety net at the Bern Muenster Terrace. Suicide and LifeThreatening Behavior 2005;35:460-7.

\section{Sinyor 2010 \{published data only\}}

Sinyor M, Levitt AJ. Effect of a barrier at Bloor Street Viaduct on suicide rates in Toronto: natural experiment. BMJ 2010;341:c2884.

* Sinyor M, Schaffer A, Redelmeier DA, Kiss A, Nishikawa Y, Cheung $\mathrm{AH}$, et al. Did the suicide barrier work after all? Revisiting the Bloor Viaduct natural experiment and its impact on suicide rates in Toronto. BMJ Open 2017;7(5):e015299.

Skegg 2009 \{published data only\}

Skegg K, Herbison P. Effect of restricting access to a suicide jumping site. Australian and New Zealand Journal of Psychiatry 2009;43:498-502.

Whitmer 2013 \{published data only\}

Whitmer DA, Woods DL. Analysis of the cost effectiveness of a suicide barrier on the Golden Gate Bridge. Crisis - The Journal of Crisis Intervention and Suicide Prevention 2013;34:98-106.

\section{References to studies excluded from this review}

Cantor 1990 \{published data only\}

Cantor $\mathrm{CH}$, Hill MA. Suicide from river bridges. Australian \& New Zealand Journal of Psychiatry 1990;24(3):377-80.

Caulkins 2015 \{published data only\}

Caulkins CG. Bridge over troubled discourse: The influence of the Golden Gate Bridge on community discourse and suicide. Journal of Aggression, Conflict and Peace Research 2015;7(1):47-56.

Chung 2016 \{published data only\}

Chung YW, Kang SJ, Matsubayashi T, Sawada Y, Ueda M. The effectiveness of platform screen doors for the prevention of subway suicides in South Korea. Journal of Affective Disorders 2016;194:80-3. 
Coman 2000 \{published data only\}

Coman M, Meyer AD, Cameron PA. Jumping from the Westgate Bridge, Melbourne. Medical Journal of Australia 2000;172(2):67-9.

\section{Copeland 1989 \{published data only\}}

Copeland AR. Suicide by jumping from buildings. American Journal of Forensic Medicine and Pathology 1989;10(4):295-8.

\section{de Moore 1999 \{published data only\}}

de Moore GM, Robertson AR. Suicide attempts by firearms and by leaping from heights: a comparative study of survivors. American Journal of Psychiatry 1999;156(9):1425-31.

\section{Durgahee 2017 \{published data only\}}

Durgahee S, Isaac M, Anderson J. Suicide by jumping at Beachy Head in East Sussex - The impact of a suicide prevention patrol scheme. European Psychiatry 2017;41:S886-7.

\section{Glatt 1986 \{published data only\}}

Glatt KM, Sherwood DW, Amisson TJ. Telephone helplines at a suicide site. Hospital \& Community Psychiatry 1986;37(2):178-80.

\section{Glatt 1987 \{published data only\}}

Glatt KM. Helpline: suicide prevention at a suicide site. Suicide \& Life-Threatening Behavior 1987;17(4):299-309.

Glowa-Kollisch 2014 \{published data only\}

Glowa-Kollisch S, Lim S, Summers C, Cohen L, Selling D, Venters H. Beyond the Bridge: Evaluating a Novel Mental Health Program in the New York City Jail System. American Journal of Public Health 2014;104(11):2212-18.

\section{Gore-Jones 2012 \{published data only\}}

Gore-Jones V, O'Callaghan J. Suicide attempts by jumping from a height: a consultation liaison experience. Australasian Psychiatry 2012;20(4):309-12.

\section{Habenstein 2013 \{published data only\}}

Habenstein A, Steffen T, Bartsch C, Michaud K, Reisch T. Chances and limits of method restriction: a detailed analysis of suicide methods in Switzerland. Archives of Suicide Research 2013;17(1):75-87.

\section{Isaacs 2016a $\{$ published data only\}}

Isaacs A, Sutton K. An Aboriginal youth suicide prevention project in rural Victoria. Advances in Mental Health 2016;14(2):118-25.

\section{Joffe 2008 \{published data only\}}

Joffe P. An empirically supported program to prevent suicide in a college student population. Suicide and Life-Threatening Behavior 2008;38(1):87-103.

\section{Jones 2015 \{published data only\}}

Jones S, Walker C, Miles AC, De Silva E, Zimitat C. A rural, community-based suicide awareness and intervention program. Rural \& Remote Health 2015;15(1):2972.
King 2005 \{published data only\}

King E, Frost N. The New Forest Suicide Prevention Initiative (NFSPI). Crisis: Journal of Crisis Intervention \& Suicide 2005;26(1):25-33.

\section{Law 2011 \{published data only\}}

Law CK, Yip PS. An economic evaluation of setting up physical barriers in railway stations for preventing railway injury: evidence from Hong Kong. Journal of Epidemiology and Community Health 2011;65(10):915-20.

\section{Leggatt 2016 \{published data only\}}

Leggatt J. Suicide prevention in Nehiyawi (Cree) comic books. Bookbird-a Journal of International Childrens Literature 2016;54(1):31-41.

\section{Lester 2005 \{published data only\}}

Lester D. Suicide by jumping from bridges. Perceptual \& Motor Skills 2005;100(3):628

\section{Lung 2017 \{published data only\}}

Lung FW, Liao SC, Wu CY, Lee MB. The effectiveness of suicide prevention programmes: urban and gender disparity in agespecific suicide rates in a Taiwanese population. Public Health 2017;147:136-43.

\section{Marin 2009 \{published data only\}}

Marin CM. The negative implications of a suicide barrier on the golden gate bridge. Dissertation Abstracts International: Section B: The Sciences and Engineering 2009;69(12):7855.

Markianos 2009 \{published data only\}

Markianos M, Tripodianakis J, Istikoglou C, Rouvali O, Christopoulos M, Papageorgopoulos P, et al. Suicide attempt by jumping: a study of gonadal axis hormones in male suicide attempters versus men who fell by accident. Psychiatry Research 2009;170(1):82-5.

\section{Mayer 2006 \{published data only\}}

Mayer L, Meuli M, Lips U, Frey B. The silent epidemic of falls from buildings: Analysis of risk factors. Pediatric Surgery International 2006;22(9):743-8.

McLean 2012 \{published data only\}

McLean SF, Tyroch AH. Injuries sustained after falls from bridges across the United States - Mexico border at El Paso. Revista Panamericana de Salud Publica/Pan American Journal of Public Health 2012;31(5):427-34

\section{Nowers 1996 \{published data only\}}

Nowers M, Gunnell D. Suicide from the Clifton Suspension Bridge in England. Journal of Epidemiology \& Community Health 1996;50(1):30-2.

\section{Omer 2001 \{published data only\}}

Omer $\mathrm{H}$, Elitzur AC. What would you say to the person on the roof? A suicide prevention text. Suicide and Life-Threatening Behavior 2001;31(2):129-39. 
Owens 2009 \{published data only\}

Owens C, Lloyd-Tomlins S, Emmens T, Aitken P. Suicides in public places: findings from one English county. European Journal of Public Health 2009;19(6):580-2.

\section{Peng 2014 \{published data only\}}

Peng TA, Lee CC, Lin JC, Shun CT, Shaw KP, Weng TI. Fatal falls from height in Taiwan. Journal of Forensic Sciences 2014;59(4):978-82.

\section{Reisch 2007 \{published data only\}}

Reisch T, Schuster U, Michel K. Suicide by jumping and accessibility of bridges: results from a national survey in Switzerland. Suicide and Life-Threatening Behavior 2007;37(6):681-7.

\section{Reisch 2008 \{published data only\}}

Reisch T, Schuster U, Michel K. Suicide by jumping from bridges and other heights: social and diagnostic factors. Psychiatry Research 2008;161(1):97-104.

\section{Retamero 2014 \{published data only\}}

Retamero C, Walsh L, Otero-Perez G. Use of the film The Bridge to augment the suicide curriculum in undergraduate medical education. Academic Psychiatry 2014;38(5):605-10.

\section{Rosen 1975 \{published data only\}}

Rosen DH. Suicide survivors. A follow up study of persons who survived jumping from the Golden Gate and San Francisco Oakland Bay Bridges. Western Journal of Medicine 1975;122(4):289-94.

\section{Saeheim 2017 \{published data only\}}

Saeheim A, Hestetun I, Mork E, Nrugham L, Mehlum L. A 12-year national study of suicide by jumping from bridges in Norway. Archives of Suicide Research 2017;21(4):568-76.

\section{Seiden 1978 \{published data only\}}

Seiden $\mathrm{RH}$. Where are they now? A follow-up study of suicide attempters from the Golden Gate Bridge. Suicide \& LifeThreatening Behavior 1978;8(4):203-16.

\section{Stack 2015 \{published data only\}}

Stack S. Crisis phones-suicide prevention versus suggestion/ contagion effects: Skyway Bridge, 1954-2012. Crisis: The Journal of Crisis Intervention and Suicide Prevention 2015;36(3):220-4.

\section{Xing 2019 \{published data only\}}

Xing Y, Lu J, Chen S. Evaluating the effectiveness of platform screen doors for preventing metro suicides in China. Journal of Affective Disorders 2019;253:63-8.

\section{Additional references}

\section{Ajdacic-Gross 2008}

Ajdacic-Gross V, Weiss MG, Ring M, Hepp U, Bopp M, Gutzwiller F, et al. Methods of suicide: international suicide patterns derived from the WHO mortality database. Bulletin of the World Health Organization 2008; Vol. 86, issue 9:726-32.

\section{Balshem 2011}

Balshem H, Helfand M, Schünemann HJ, Oxman AD, Kunz R, Brozek J, et al. GRADE guidelines: 3. Rating the quality of evidence. Journal of Clinical Epidemiology 2011;64(4):401-6

\section{Beautrais 2001}

Beautrais AL. Effectiveness of barriers at suicide jumping sites: a case study. Australian and New Zealand Journal of Psychiatry 2001;35(5):557-62.

\section{Beautrais 2007}

Beautrais AL. Suicide by jumping: a review of research and prevention strategies. Hogrefe \& Huber Publishers 2007;28(Suppl 1):58-63.

\section{Cox 2013}

Cox GR, Owens C, Robinson J, Nicholas A, Lockley A, Williamson $\mathrm{M}$, et al. Interventions to reduce suicides at suicide hotspots: a systematic review. BMC Public Health 2013;13(1):214

\section{Daigle 2005}

Daigle MS. Suicide prevention through means restriction: Assessing the risk of substitution: A critical review and synthesis. Accident Analysis \& Prevention 2005;37:625-32.

\section{Drummond 1996}

Drummond MF, Jefferson TO. Guidelines for authors and peer reviewers of economic submissions to the BMJ. The BMJ Economic Evaluation Working Party. BMJ 1996;313:275-83.

\section{Egger 1997}

Egger M, Smith GD, Schneider M, Minder C. Bias in meta-analysis detected by a simple, graphical test. $B M J$ 1997;315(7109):629-34.

\section{Elnour 2008}

Elnour AA, Harrison J. Lethality of suicide methods. Injury Prevention 2008;14:39-45.

\section{Geulayov 2016}

Geulayov G, Kapur N, Turnbull P, Clements C, Waters K, Ness J, et al. Epidemiology and trends in non-fatal self-harm in three centres in England, 2000-2012: findings from the Multicentre Study of Self-harm in England. BMJ Open 2016;6(e010538):1-8.

\section{Gunnell 1997}

Gunnell D, Nowers M. Suicide by jumping. Acta Psychiatrica Scandinavica 1997;96:1-6.

\section{Hawkins 2007}

Hawkins LC, Edwards JN, Dargan PI. Impact of Restricting Paracetamol Pack Sizes on Paracetamol Poisoning in the United Kingdom. Drug Safety 2007;30(6):465-79.

\section{Hawton 2005}

Hawton K. Restriction of access to methods of suicide as a means of suicide prevention. Prevention and treatment of suicidal behaviour from Science to practice. Oxford, UK: Oxford University Press, 2005:279-91. 


\section{Hawton 2007}

Hawton K. Restricting access to methods of suicide - Rationale and evaluation of this approach to suicide prevention. Crisis 2007;28:4-9.

\section{Hawton 2008}

Hawton K, Harriss L. The changing gender ratio in occurrence of deliberate self-harm across the lifecycle. Crisis 2008;29(1):4-10.

\section{Hawton 2009}

Hawton K, van Heeringen K. Suicide. The Lancet 2009;373(9672):1372-81.

\section{Hawton 2016}

Hawton K, Witt KG, Salisbury TLT, Arensman E, Gunnell D, Hazell $P$, et al. Psychosocial interventions for self-harm in adults. Cochrane Database of Systematic Reviews 2016, Issue 5. [DOI: 10.1002/14651858.CD012189]

\section{Higgins 2011}

Higgins JP, Green S, editor(s). Cochrane Handbook for Systematic Reviews of Interventions Version 5.1.0 (updated March 2011). The Cochrane Collaboration, 2011. Available from handbook.cochrane.org. The Cochrane Collaboration.

\section{John 2017}

John A, Hawton K, Gunnell D, Lloyd K, Scourfield J, Jones PA, et al. Newspaper Reporting on a Cluster of Suicides in the UK. Crisis-the Journal of Crisis Intervention and Suicide Prevention 2017;38:17-25.

\section{Kreitman 1976}

Kreitman N. The coal gas story. United Kingdom suicide rates, 1960-71. British Journal of Preventive \& Social Medicine 1976;30(2):86-93.

\section{Moher 2010}

Moher D, Liberati A, Tetzlaff J, Altman DG. Preferred reporting items for systematic reviews and meta-analyses: The PRISMA statement. International Journal of Surgery 2010;8:336-41.

\section{NICE 2011}

National Institute for Health and Care Excellence. Self-harm in over 8s: long-term management. Clinical guideline [CG133] 2011.

\section{NICE 2018}

National Institute for Health and Care Excellence. Preventing suicide in community and custodial settings: Evidence review 6 for reducing access to means. NICE guideline [NG105] 2018.

\section{Okolie 2017}

Okolie C, Dennis M, Simon TE, John A. A systematic review of interventions to prevent suicidal behaviors and reduce suicidal ideation in older people. International Psychogeriatrics 2017;29:1801-24.

\section{Pirkis 2013}

Pirkis J, Spittal MJ, Cox G, Robinson J, Cheung YT, Studdert D. The effectiveness of structural interventions at suicide hotspots: a meta-analysis. International Journal of Epidemiology 2013;42:541-8.

\section{Pirkis 2015}

Pirkis J, Too LS, Spittal MJ, Krysinska K, Robinson J, Cheung YT. Interventions to reduce suicides at suicide hotspots: a systematic review and meta-analysis. Lancet Psychiatry 2015;2(11):994-1001.

\section{R Development Core Team 2017 [Computer program]}

R Development Core Team. R: A language and environment for statistical computing. Version 3.4.3. Vienna: Austria R Foundation for Statistical Computing, 2017.

\section{Schünemann 2011}

Schünemann HJ, Oxman AD, Vist GE, Higgins JP, Deeks JJ, Glasziou P, et al. Chapter 12: Interpreting results and drawing conclusions. In: Higgins JP, Green S, editor(s). Cochrane Handbook for Systematic Reviews of Interventions Version 5.1.0 (updated March 2011). The Cochrane Collaboration, 2011. Available from handbook.cochrane.org. Wiley-Blackwell.

\section{Sinclair 2010}

Sinclair JMA, Hawton K, Gray A. Six year follow-up of a clinical sample of self-harm patients. Journal of affective disorders 2010;121(3):247-252.

\section{Spittal 2015}

Spittal MJ, Pirkis J, Gurrin LC. Meta-analysis of incidence rate data in the presence of zero events. BMC Medical Research Methodology 2015;15:42.

\section{Sterne 2016a}

Sterne JA, Hernán MA, Reeves BC, Savović J, Berkman ND, Viswanathan M, et al. ROBINS-I: a tool for assessing risk of bias in non-randomised studies of interventions. BMJ 2016;355:i4919.

\section{Sterne 2016b}

Sterne JA, Higgins JP, Elbers RG, Reeves BC, The Development Group for ROBINS-I. Risk of bias in non-randomized studies of interventions (ROBINS-I): detailed guidance. www.riskofbias.info (accessed prior to 31 October 2019).

\section{Turecki 2016}

Turecki G, Brent DA. Suicide and suicidal behaviour. Lancet 2016;387:1227-39.

\section{WHO 2014}

World Health Organization. Preventing Suicide: A Global Imperative. WHO Library Cataloguing-in-Publication Data 2014.

\section{WHO 2018}

World Health Organization. Suicide: Fact sheet [online]. www.who.int/en/news-room/fact-sheets/detail/suicide (accessed 27 September 2018).

\section{WHO 2019}

World Health Organization. Suicide in the world: Global Health Estimates. WHO Geneva https://www.who.int/publicationsdetail/suicide-in-the-world (accessed 25 November 2019). 


\section{Wong 2014}

Wong PW, Caine ED, Lee CK, Beautrais A, Yip PS. Suicides by jumping from a height in Hong Kong: a review of coroner court files. Social Psychiatry and Psychiatric Epidemiology 2014;49:211-9.

\section{Yip 2012}

Yip PS, Caine E, Yousuf S, Chang SS, Wu KC, Chen YY. Means restriction for suicide prevention. Lancet 2012;379:2393-9.

CHARACTERISTICS OF STUDIES

Characteristics of included studies [ordered by study ID]

Beautrais 2009

$\begin{array}{ll}\text { Methods } & \text { Setting: Grafton bridge, Auckland, New Zealand } \\ & \text { Design: before-and-after study (A-B-A reversal design) }\end{array}$

Participants General population

Interventions Metal screens/mesh/glass safety barriers

Outcomes $\quad$ Suicide

\section{References to other published versions of this review John 2018}

John A, Hawton K, Okolie C, Dennis M, Price SF, Lloyd K. Means restriction for the prevention of suicide: generic protocol. Cochrane Database of Systematic Reviews 2018, Issue 4. [DOI: 10.1002/14651858.CD012995]

* Indicates the major publication for the study

Notes This study employed an A-B-A reversal design. The observation periods were: five-year period original barriers were in place (1991-1995), six-year period original barriers were removed (1997-2002) and the four-year period new barriers were reinstalled (2003-2006). Data for suicide deaths by jumping from the Grafton bridge were obtained from the Department of Court's coronial records, and the mortality database of the New Zealand Health Information Service.

The original barriers did not extend across the full length of the bridge while the new barriers extended the entire length of the bridge.

Beautrais 2001 and Beautrais 2009 relied on the same core data and have been grouped together and not discussed as individual studies.

\section{Bennewith 2007}

\begin{tabular}{ll}
\hline Methods & $\begin{array}{l}\text { Setting: Clifton suspension bridge, Bristol, UK } \\
\text { Design: before-and-after study }\end{array}$ \\
\hline Participants & General population \\
\hline Interventions & $\begin{array}{l}\text { 1. Two-metre high wire barrier consisting of metal fencing to a height of } 1.5 \mathrm{~m} \text { above which is a } 0.5 \mathrm{~m} \\
\text { high five-strand inward sloping wire fence consisting of five taut parallel wires, evenly spaced }\end{array}$ \\
$\begin{array}{ll}\text { 2. Bridge staff ensuring safety of people on the bridge and dealing with any incidents } \\
\text { 3. CCTV cameras installed on several points on bridge }\end{array}$ \\
\hline Outcomes & $\begin{array}{l}\text { 1. Suicide } \\
\text { 2. Non-fatal incidents }\end{array}$ \\
\hline
\end{tabular}


Bennewith 2007 (Continued)

Notes

Information on all suicides was obtained from Coroners' inquest files. Bennewith 2007 and Bennewith 2011 relied on the same core data and have been grouped together and not discussed as individual studies.

\section{Hemmer 2017}

Methods Setting: 15 high-frequency locations in Switzerland (13 bridges, 1 terrace and 1 multistorey car park)

Design: before-and-after study

\begin{tabular}{ll}
\hline Participants & General population \\
\hline Interventions & $\begin{array}{l}\text { 1. Barrier }(n=11) \\
\text { 2. Safety net }(n=4) \\
\text { 3. Help signs installed at } 3 \text { jumps sites (all bridges) }\end{array}$ \\
\hline Outcomes & 1. Suicide \\
\hline Notes & $\begin{array}{l}\text { Data on all suicides by jumping from heights were obtained from the Swiss Federal Office for statistics } \\
\text { (BFS). More detailed data were provided by official bodies such as regional forensic institutes, cantonal } \\
\text { and district doctors, as well as police authorities. } \\
\text { Of the } 11 \text { barrier interventions, } 5 \text { were complete measures, i.e. secured the entire jump area. } \\
\text { Of the } 4 \text { safety net interventions, } 2 \text { were complete measures. }\end{array}$ \\
\hline
\end{tabular}

Isaac 2005

\begin{tabular}{ll}
\hline Methods & $\begin{array}{l}\text { Setting: Beachy Head, Sussex, UK } \\
\text { Design: before-and-after study }\end{array}$ \\
\hline Participants & General population \\
\hline Interventions & 1. Restriction of access by car due to outbreak of foot and mouth disease \\
\hline Outcomes & 1. Suicide \\
\hline Notes & Data on suicides by jumping were abstracted from Coroners' reports \\
\hline
\end{tabular}

Law 2014

$\begin{array}{ll}\text { Methods } & \text { Setting: Gateway bridge, Brisbane, Australia } \\ & \text { Design: before-and-after study }\end{array}$

\begin{tabular}{ll}
\hline Participants & General population \\
\hline Interventions & 1. Fencing barriers fitted along the sidewalk of the bridge \\
\hline Outcomes & 1. Suicide
\end{tabular}


Law 2014 (Continued)

Notes

Data on suicide by jumping were obtained from the Queensland Suicide Register.

Original barriers were 3.3 metres high. These were replaced with a similar fence 3.6 metres high

Lester 1993

\begin{tabular}{ll}
\hline Methods & $\begin{array}{l}\text { Setting: Ellington Bridge, Washington DC, USA } \\
\text { Design: before-and-after study }\end{array}$ \\
\hline Participants & General population \\
\hline Interventions & 1. Eight foot anti-suicide fence barrier \\
\hline Outcomes & 1. Suicide \\
\hline Notes & $\begin{array}{l}\text { Lester } 1993 \text { and O'Carroll } 1994 \text { relied on the same core data and have been grouped together and not } \\
\text { discussed as individual studies. }\end{array}$ \\
\hline
\end{tabular}

\section{Lockley 2014}

\begin{tabular}{ll}
\hline Methods & $\begin{array}{l}\text { Setting: Gap Park, Sydney, Australia } \\
\text { Design: before-and-after study }\end{array}$ \\
\hline Participants & General population \\
\hline Interventions & $\begin{array}{l}\text { 1. } 130 \text { centimetre high fence along cliff-tops. Fence consisted of inward curved wire mesh and a wooden } \\
\text { handrail, and did not offer footholds }\end{array}$ \\
$\begin{array}{l}\text { 2. Crisis telephones and signs displaying a dedicated lifeline telephone number } \\
\text { 3. CCTV cameras }\end{array}$ \\
\hline
\end{tabular}

\begin{tabular}{ll}
\hline Outcomes & 1. Suicide \\
\hline Notes & Data on suicides at Gap Park were abstracted from the National Coroners Information System (NCIS) \\
\hline
\end{tabular}

\section{Mohl 2012}

\begin{tabular}{ll}
\hline Methods & $\begin{array}{l}\text { Setting: Cantonal Hospital of Baden, Switzerland } \\
\text { Design: before-and-after study }\end{array}$ \\
\hline Participants & Hospital inpatients \\
\hline Interventions & 1. Twenty millimetre diameter metal guard rail installed at each of the 1240 hospital windows \\
\hline Outcomes & 1. Suicide \\
\hline Notes & Data on suicides by jumping were collected from police records and hospital patient charts. \\
& The metal rail was placed at a height of $113 \mathrm{~cm}, 18 \mathrm{~cm}$ above the window sill.
\end{tabular}


Pelletier 2007

\begin{tabular}{ll}
\hline Methods & $\begin{array}{l}\text { Setting: Memorial Bridge in Augusta, Maine, USA } \\
\text { Design: before-and-after study }\end{array}$ \\
\hline Participants & General population \\
\hline Interventions & 1. Eleven foot high safety fence installed on each side of the bridge \\
\hline Outcomes & 1. Suicide \\
\hline Notes & $\begin{array}{l}\text { Data on all suicides during the study period were obtained from death certificates using ICD codes for } \\
\text { suicide }\end{array}$ \\
\hline
\end{tabular}

Perron 2013

\begin{tabular}{ll}
\hline Methods & $\begin{array}{l}\text { Setting: Jacques-Cartier Bridge, Montreal Quebec, Canada } \\
\text { Design: before-and-after study }\end{array}$ \\
\hline Participants & General population \\
\hline Interventions & 1. A steel palisade fencing barrier \\
\hline Outcomes & 1. Suicide rates \\
\hline Notes & Data on suicides were extracted from the data banks of the Quebec chief coroners' office. \\
& The barrier was extended from 1.1 metres to 1.4 metres, and curved inwardly at the top
\end{tabular}

\section{Reisch 2005}

Methods Setting: Muenster Terrace, Bern, Switzerland

Design: before-and-after study

\begin{tabular}{ll}
\hline Participants & General population \\
\hline Interventions & 1. Four meter wide metal mesh safety net \\
\hline Outcomes & $\begin{array}{l}\text { 1. Suicide } \\
\text { 2. Media reports of suicide }\end{array}$ \\
\hline Notes & Data on all officially confirmed suicides were extracted from the Swiss Federal Office for Statistics \\
\hline
\end{tabular}

\section{Sinyor 2010}

$\begin{array}{ll}\text { Methods } & \text { Setting: Bloor Street Viaduct, Toronto, Canada } \\ & \text { Design: before-and-after study }\end{array}$


Sinyor 2010 (Continued)

\begin{tabular}{ll} 
Participants & General Population \\
\hline Interventions & $\begin{array}{l}\text { 1. A five-metre high barrier consisting of thousands of thin steel rods spaced closely together and sup- } \\
\text { ported externally by an angled steel frame }\end{array}$ \\
\hline Outcomes & 1. Suicide rates \\
\hline Notes & $\begin{array}{l}\text { Data on suicides were extracted from chief coroners' office records. Sinyor } 2010 \text { and Sinyor } 2017 \text { relied } \\
\text { on the same core data and have been grouped together and not discussed as individual studies. }\end{array}$
\end{tabular}

\section{Skegg 2009}

\begin{tabular}{ll} 
Methods & $\begin{array}{l}\text { Setting: Lawyer's Head, Dunedin, New Zealand } \\
\text { Design: before-and-after study }\end{array}$ \\
\hline Participants & General population \\
\hline Interventions & Temporary road closure preventing vehicular access to the headland \\
\hline Outcomes & $\begin{array}{l}\text { 1. Suicide } \\
\text { 2. Police callouts for threatened suicide }\end{array}$ \\
\hline Notes & $\begin{array}{l}\text { Deaths at the headland were extracted using records from the local police inquest officer, the coroner's } \\
\text { pathologist and Marine Search and Rescue. }\end{array}$ \\
\hline
\end{tabular}

Whitmer 2013

\begin{tabular}{ll}
\hline Methods & $\begin{array}{l}\text { Setting: Golden Gate Bridge, USA } \\
\text { Design: cost-effectiveness analysis }\end{array}$ \\
\hline Participants & General population \\
\hline Interventions & 1. A physical barrier on the Golden Gate Bridge \\
\hline Outcomes & \begin{tabular}{l} 
1. Suicides by method in San Francisco \\
2. Suicides from the Golden Gate Bridge \\
3. Suicide method lethality \\
4. Reductions in mortality \\
\hline Sutes
\end{tabular} $\begin{array}{l}\text { Suicide data were obtained from the San Francisco Medical Examiner's annual reports and Marin Coun- } \\
\text { San Francisco and Golden Gate Bridge suicides were reviewed over a 70-year period (1936-2006). Esti- } \\
\text { mates of the number of lives saved and the cost of barrier construction and maintenance were used to } \\
\text { calculate the cost per life saved over a 20-year period. }\end{array}$ \\
\hline
\end{tabular}

ICD: International Classification of Diseases

Characteristics of excluded studies [ordered by study ID] 


\begin{tabular}{|c|c|}
\hline Study & Reason for exclusion \\
\hline Cantor 1990 & No intervention reported. No effectiveness data \\
\hline Caulkins 2015 & $\begin{array}{l}\text { Focus is on theory and its application in suicide prevention. No intervention reported. No effective- } \\
\text { ness data }\end{array}$ \\
\hline Chung 2016 & Intervention aimed at reducing rail/subway suicides \\
\hline Coman 2000 & $\begin{array}{l}\text { Focus is on demographic and clinical characteristics of people who jumped from bridge. No inter- } \\
\text { vention reported. No effectiveness data }\end{array}$ \\
\hline Copeland 1989 & $\begin{array}{l}\text { Focus is on demographic and clinical characteristics of people who jumped from buildings. No in- } \\
\text { tervention reported. No effectiveness data }\end{array}$ \\
\hline de Moore 1999 & $\begin{array}{l}\text { Focus is on demographic and clinical characteristics of people who died by suicide by jumping or } \\
\text { firearms. No intervention reported. No effectiveness data }\end{array}$ \\
\hline Durgahee 2017 & $\begin{array}{l}\text { Intervention solely aimed at increasing the likelihood of intervention by a third party. No effective- } \\
\text { ness data }\end{array}$ \\
\hline Glatt 1986 & Intervention solely aimed at encouraging help-seeking \\
\hline Glatt 1987 & Intervention solely aimed at encouraging help-seeking \\
\hline Glowa-Kollisch 2014 & Cognitive behaviour therapy-based intervention \\
\hline Gore-Jones 2012 & $\begin{array}{l}\text { Focus is on demographic and clinical characteristics of people who attempted suicide by jumping. } \\
\text { No intervention reported. No effectiveness data }\end{array}$ \\
\hline Habenstein 2013 & No intervention reported. Focus is on accessibility of suicides to method restriction \\
\hline Isaacs 2016a & Intervention aimed at educating the public \\
\hline Joffe 2008 & Intervention is not means restriction. Mandated professional assessment of suicidal students \\
\hline Jones 2015 & Community-based and gatekeeper educational intervention \\
\hline King 2005 & Intervention solely aimed at encouraging help-seeking \\
\hline Law 2011 & Intervention aimed at reducing rail/subway suicides \\
\hline Leggatt 2016 & Intervention aimed at educating the public \\
\hline Lester 2005 & $\begin{array}{l}\text { Intervention aimed at encouraging help-seeking and increasing the likelihood of intervention by a } \\
\text { third party }\end{array}$ \\
\hline Lung 2017 & Intervention included risk assessment and gatekeeper training \\
\hline Marin 2009 & Intervention aimed at training professionals \\
\hline Markianos 2009 & No intervention reported. Focus is on levels of plasma sex hormones \\
\hline Mayer 2006 & No intervention reported. Focus is on accidental falls from buildings \\
\hline McLean 2012 & No intervention reported. Included accidental falls \\
\hline
\end{tabular}




\begin{tabular}{|c|c|}
\hline Study & Reason for exclusion \\
\hline Nowers 1996 & $\begin{array}{l}\text { Focus is on demographic and clinical characteristics of people who attempted suicide by jumping. } \\
\text { No intervention reported. No effectiveness data }\end{array}$ \\
\hline Omer 2001 & Intervention aimed at educating the public \\
\hline Owens 2009 & Epidemiological study. No intervention reported. No effectiveness data \\
\hline Peng 2014 & No intervention reported. Included accidental falls \\
\hline Reisch 2007 & No intervention reported \\
\hline Reisch 2008 & $\begin{array}{l}\text { Focus is on social and diagnostic characteristics of people who attempted suicide by jumping. No } \\
\text { intervention reported. No effectiveness data }\end{array}$ \\
\hline Retamero 2014 & Intervention aimed at educating students \\
\hline Rosen 1975 & No intervention reported. Focus is on experiences of survivors of jumps \\
\hline Saeheim 2017 & Unclear study observation periods \\
\hline Seiden 1978 & No intervention reported. Focused on long-term mortality experiences of suicide attempters \\
\hline Stack 2015 & Intervention solely aimed at encouraging help-seeking \\
\hline Xing 2019 & Intervention aimed at reducing rail/subway suicides (not covered in this review) \\
\hline
\end{tabular}

\section{ADDITIONAL TABLES}

Table 1. Pre- and postintervention suicides and annual average suicides per year (observational studies)

\begin{tabular}{|c|c|c|c|c|c|c|}
\hline \multirow[t]{2}{*}{ Author and year } & \multicolumn{2}{|c|}{$\begin{array}{l}\text { Observation period } \\
\text { (years) }\end{array}$} & \multicolumn{2}{|c|}{ Total suicides } & \multicolumn{2}{|c|}{ Suicides per year } \\
\hline & $\begin{array}{l}\text { Pre-inter- } \\
\text { vention }\end{array}$ & $\begin{array}{l}\text { Post-in- } \\
\text { terven- } \\
\text { tion }\end{array}$ & $\begin{array}{l}\text { Pre-inter- } \\
\text { vention }\end{array}$ & $\begin{array}{l}\text { Post-in- } \\
\text { terven- } \\
\text { tion }\end{array}$ & $\begin{array}{l}\text { Pre-inter- } \\
\text { vention }\end{array}$ & $\begin{array}{l}\text { Post-in- } \\
\text { terven- } \\
\text { tion }\end{array}$ \\
\hline Beautrais 2001/Beautrais 2009 & 6 & 4 & 19 & 0 & 3.2 & 0 \\
\hline Bennewith 2007/Bennewith 2011 & 5 & 5 & 41 & 20 & 8.2 & 4 \\
\hline Hemmer 2017 & 14.9 & 6.1 & 21.8 & 2.5 & 1.5 & 0.4 \\
\hline Isaac 2005 & 15 & 0.4 & 230 & 0 & 15.3 & 0 \\
\hline Law 2014 & 4 & 19 & 22 & 16 & 5.5 & 0.8 \\
\hline Lester 1993/O'Carroll 1994 & 7 & 5 & 25 & 1 & 3.6 & 0.2 \\
\hline Lockley 2014 & 10.6 & 2.4 & 79 & 16 & 7.5 & 6.7 \\
\hline Mohl 2012 & 9.5 & 6.5 & 10 & 1 & 1.1 & 0.2 \\
\hline
\end{tabular}


Table 1. Pre- and postintervention suicides and annual average suicides per year (observational studies) (Continued)

\begin{tabular}{|c|c|c|c|c|c|c|}
\hline Pelletier 2007 & 22 & 22 & 14 & 0 & 0.6 & 0 \\
\hline Perron 2013 & 15.5 & 5 & 155 & 13 & 10 & 2.6 \\
\hline Reisch 2005 & 4 & 4 & 8 & 0 & 2 & 0 \\
\hline Sinyor 2010/Sinyor 2017 & 11 & 11 & 104.5 & 1.1 & 9.5 & 0.1 \\
\hline Skegg 2009 & 10 & 2 & 13 & 0 & 1.3 & 0 \\
\hline Total & 134.5 & 92.4 & 742.3 & 70.6 & 5.5 & 0.8 \\
\hline
\end{tabular}

Table 2. Risk of bias - Beautrais 2001/Beautrais 2009

\begin{tabular}{|c|c|c|}
\hline Domain & $\begin{array}{l}\text { Authors' judge- } \\
\text { ment }\end{array}$ & Support for judgement \\
\hline Bias due to confounding & Moderate risk & $\begin{array}{l}\text { The study did not take into account the possibility of potential confounding ef- } \\
\text { fects as a result of media publicity which could have promoted the jump site }\end{array}$ \\
\hline $\begin{array}{l}\text { Bias in selection of partici- } \\
\text { pants/data }\end{array}$ & Low risk & $\begin{array}{l}\text { The study assessed interventions that were aimed at the general population, } \\
\text { therefore all individuals who would have been eligible to take part in the study } \\
\text { were included }\end{array}$ \\
\hline $\begin{array}{l}\text { Bias in classification of in- } \\
\text { terventions }\end{array}$ & Low risk & Intervention status is well defined \\
\hline $\begin{array}{l}\text { Bias due to deviations } \\
\text { from intended interven- } \\
\text { tions }\end{array}$ & Low risk & $\begin{array}{l}\text { There were no deviations from the intended interventions that were likely to im- } \\
\text { pact on the outcome }\end{array}$ \\
\hline Bias due to missing data & Moderate risk & $\begin{array}{l}\text { The analysis is unlikely to have removed the risk of bias arising from the missing } \\
\text { data. Data were unavailable for suicides after } 1998\end{array}$ \\
\hline $\begin{array}{l}\text { Bias in measurement of } \\
\text { outcomes }\end{array}$ & Low risk & $\begin{array}{l}\text { The methods of outcome assessment were comparable across intervention peri- } \\
\text { ods }\end{array}$ \\
\hline $\begin{array}{l}\text { Bias in selection of report- } \\
\text { ed result }\end{array}$ & Unclear risk & $\begin{array}{l}\text { No access to study protocols for this study, therefore it is difficult to assess this } \\
\text { domain }\end{array}$ \\
\hline
\end{tabular}

Low risk of bias: the study is comparable to a well-performed randomised trial with regard to this domain.

Moderate risk of bias: the study is sound for a non-randomised study with regard to this domain but cannot be considered comparable to a well-performed randomised trial.

Unclear risk of bias: too few details are available to make a judgement of 'critical', 'serious', 'moderate', or 'low' risk

Table 3. Risk of bias - Bennewith 2007/Bennewith 2011

$\begin{array}{ll}\text { Domain } & \begin{array}{l}\text { Authors' judge- Support for judgement } \\ \text { ment }\end{array}\end{array}$


Table 3. Risk of bias - Bennewith 2007/Bennewith 2011 (Continued)

\begin{tabular}{lll} 
Bias due to confounding & Moderate risk & $\begin{array}{l}\text { The study did not take into account the possibility of potential confounding ef- } \\
\text { fects as a result of media publicity which could have promoted the jump site }\end{array}$ \\
\hline $\begin{array}{l}\text { Bias in selection of partici- } \\
\text { pants/data }\end{array}$ & Low risk & $\begin{array}{l}\text { The study assessed interventions that were aimed at the general population, } \\
\text { therefore all individuals who would have been eligible to take part in the study } \\
\text { were included }\end{array}$ \\
\hline $\begin{array}{l}\text { Bias in classification of in- } \\
\text { terventions }\end{array}$ & Low risk & Intervention status is well defined \\
\hline $\begin{array}{l}\text { Bias due to deviations from } \\
\text { intended interventions }\end{array}$ & Low risk & $\begin{array}{l}\text { There were no deviations from the intended interventions that were likely to im- } \\
\text { pact on the outcome }\end{array}$ \\
\hline $\begin{array}{l}\text { Bias due to missing data } \\
\text { Moderate risk }\end{array}$ & $\begin{array}{l}\text { The analysis is unlikely to have removed the risk of bias arising from the missing } \\
\text { data }\end{array}$ \\
\hline $\begin{array}{l}\text { Bias in measurement of out- } \\
\text { comes }\end{array}$ & Low risk & $\begin{array}{l}\text { The methods of outcome assessment were comparable across intervention pe- } \\
\text { riods }\end{array}$ \\
\hline $\begin{array}{l}\text { Bias in selection of reported } \\
\text { result }\end{array}$ & Unclear risk & $\begin{array}{l}\text { No access to study protocols for this study therefore it is difficult to assess this } \\
\text { domain }\end{array}$ \\
\hline
\end{tabular}

Low risk of bias: the study is comparable to a well-performed randomised trial with regard to this domain.

Moderate risk of bias: the study is sound for a non-randomised study with regard to this domain but cannot be considered comparable to a well-performed randomised trial.

Unclear risk of bias: too few details are available to make a judgement of 'critical', 'serious', 'moderate', or 'low' risk

Table 4. Risk of bias - Hemmer 2017

\begin{tabular}{|c|c|c|}
\hline Domain & $\begin{array}{l}\text { Authors' judge- } \\
\text { ment }\end{array}$ & Support for judgement \\
\hline Bias due to confounding & Moderate risk & $\begin{array}{l}\text { The study did not take into account the possibility of potential confounding } \\
\text { effects as a result of media publicity which could have promoted the jump } \\
\text { site }\end{array}$ \\
\hline $\begin{array}{l}\text { Bias in selection of partici- } \\
\text { pants/data }\end{array}$ & Low risk & $\begin{array}{l}\text { The study assessed interventions that were aimed at the general popula- } \\
\text { tion, therefore all individuals who would have been eligible to take part in the } \\
\text { study were included }\end{array}$ \\
\hline $\begin{array}{l}\text { Bias in classification of inter- } \\
\text { ventions }\end{array}$ & Low risk & Intervention status is well defined \\
\hline $\begin{array}{l}\text { Bias due to deviations from in- } \\
\text { tended interventions }\end{array}$ & Low risk & $\begin{array}{l}\text { There were no deviations from the intended interventions that were likely to } \\
\text { impact on the outcome }\end{array}$ \\
\hline Bias due to missing data & Low risk & Data were reasonably complete \\
\hline $\begin{array}{l}\text { Bias in measurement of out- } \\
\text { comes }\end{array}$ & Low risk & $\begin{array}{l}\text { The methods of outcome assessment were comparable across intervention } \\
\text { periods }\end{array}$ \\
\hline $\begin{array}{l}\text { Bias in selection of reported } \\
\text { result }\end{array}$ & Unclear risk & $\begin{array}{l}\text { No access to study protocols for this study therefore it is difficult to assess } \\
\text { this domain }\end{array}$ \\
\hline
\end{tabular}

Low risk of bias: the study is comparable to a well-performed randomised trial with regard to this domain. 
Moderate risk of bias: the study is sound for a non-randomised study with regard to this domain but cannot be considered comparable to a well-performed randomised trial.

Unclear risk of bias: too few details are available to make a judgement of 'critical', 'serious', 'moderate', or 'low' risk

Table 5. Risk of bias - Isaac 2005

\begin{tabular}{|c|c|c|}
\hline Domain & $\begin{array}{l}\text { Authors' judge- } \\
\text { ment }\end{array}$ & Support for judgement \\
\hline Bias due to confounding & Moderate risk & $\begin{array}{l}\text { The study did not take into account the possibility of potential confounding } \\
\text { effects as a result of media publicity which could have promoted the jump } \\
\text { site }\end{array}$ \\
\hline $\begin{array}{l}\text { Bias in selection of partici- } \\
\text { pants/data }\end{array}$ & Low risk & $\begin{array}{l}\text { The study assessed interventions that were aimed at the general popula- } \\
\text { tion, therefore all individuals who would have been eligible to take part in the } \\
\text { study were included }\end{array}$ \\
\hline $\begin{array}{l}\text { Bias in classification of inter- } \\
\text { ventions }\end{array}$ & Low risk & Intervention status is well defined \\
\hline $\begin{array}{l}\text { Bias due to deviations from in- } \\
\text { tended interventions }\end{array}$ & Low risk & $\begin{array}{l}\text { There were no deviations from the intended interventions that were likely to } \\
\text { impact on the outcome }\end{array}$ \\
\hline Bias due to missing data & Low risk & Data were reasonably complete \\
\hline $\begin{array}{l}\text { Bias in measurement of out- } \\
\text { comes }\end{array}$ & Low risk & $\begin{array}{l}\text { The methods of outcome assessment were comparable across intervention } \\
\text { periods }\end{array}$ \\
\hline $\begin{array}{l}\text { Bias in selection of reported } \\
\text { result }\end{array}$ & Unclear risk & $\begin{array}{l}\text { No access to study protocols for this study therefore it is difficult to assess } \\
\text { this domain }\end{array}$ \\
\hline
\end{tabular}

Low risk of bias: the study is comparable to a well-performed randomised trial with regard to this domain.

Moderate risk of bias: the study is sound for a non-randomised study with regard to this domain but cannot be considered comparable to a well-performed randomised trial.

Unclear risk of bias: too few details are available to make a judgement of 'critical', 'serious', 'moderate', or 'low' risk

Table 6. Risk of bias - Law 2014

\begin{tabular}{|c|c|c|}
\hline Domain & $\begin{array}{l}\text { Authors' judge- } \\
\text { ment }\end{array}$ & Support for judgement \\
\hline Bias due to confounding & Moderate risk & $\begin{array}{l}\text { The study did not take into account the possibility of potential confounding ef- } \\
\text { fects as a result of media publicity which could have promoted the jump site }\end{array}$ \\
\hline $\begin{array}{l}\text { Bias in selection of partici- } \\
\text { pants/data }\end{array}$ & Low risk & $\begin{array}{l}\text { The study assessed interventions that were aimed at the general population, } \\
\text { therefore all individuals who would have been eligible to take part in the study } \\
\text { were included }\end{array}$ \\
\hline $\begin{array}{l}\text { Bias in classification of inter- } \\
\text { ventions }\end{array}$ & Low risk & Intervention status is well defined \\
\hline $\begin{array}{l}\text { Bias due to deviations from } \\
\text { intended interventions }\end{array}$ & Low risk & $\begin{array}{l}\text { There were no deviations from the intended interventions that were likely to } \\
\text { impact on the outcome }\end{array}$ \\
\hline Bias due to missing data & Moderate risk & Data prior to 1990 were not available \\
\hline
\end{tabular}


Table 6. Risk of bias - Law 2014 (Continued)
Bias in measurement of out- Low risk
The methods of outcome assessment were comparable across intervention comes periods

Bias in selection of reported Unclear risk
result

No access to study protocols for this study therefore it is difficult to assess this result domain

Low risk of bias: the study is comparable to a well-performed randomised trial with regard to this domain.

Moderate risk of bias: the study is sound for a non-randomised study with regard to this domain but cannot be considered comparable to a well-performed randomised trial.

Unclear risk of bias: too few details are available to make a judgement of 'critical', 'serious', 'moderate', or 'low' risk

Table 7. Risk of bias - Lester 1993/O'Carroll 1994

\begin{tabular}{|c|c|c|}
\hline Domain & $\begin{array}{l}\text { Authors' judge- } \\
\text { ment }\end{array}$ & Support for judgement \\
\hline Bias due to confounding & Moderate risk & $\begin{array}{l}\text { The study did not take into account the possibility of potential confounding } \\
\text { effects as a result of media publicity which could have promoted the jump } \\
\text { site }\end{array}$ \\
\hline $\begin{array}{l}\text { Bias in selection of partici- } \\
\text { pants/data }\end{array}$ & Low risk & $\begin{array}{l}\text { The study assessed interventions that were aimed at the general popula- } \\
\text { tion, therefore all individuals who would have been eligible to take part in the } \\
\text { study were included }\end{array}$ \\
\hline $\begin{array}{l}\text { Bias in classification of inter- } \\
\text { ventions }\end{array}$ & Low risk & Intervention status is well defined \\
\hline $\begin{array}{l}\text { Bias due to deviations from in- } \\
\text { tended interventions }\end{array}$ & Low risk & $\begin{array}{l}\text { There were no deviations from the intended interventions that were likely to } \\
\text { impact on the outcome }\end{array}$ \\
\hline Bias due to missing data & Low risk & Data were reasonably complete \\
\hline $\begin{array}{l}\text { Bias in measurement of out- } \\
\text { comes }\end{array}$ & Low risk & $\begin{array}{l}\text { The methods of outcome assessment were comparable across intervention } \\
\text { periods }\end{array}$ \\
\hline $\begin{array}{l}\text { Bias in selection of reported } \\
\text { result }\end{array}$ & Unclear risk & $\begin{array}{l}\text { No access to study protocols for this study therefore it is difficult to assess } \\
\text { this domain }\end{array}$ \\
\hline
\end{tabular}

Low risk of bias: the study is comparable to a well-performed randomised trial with regard to this domain.

Moderate risk of bias: the study is sound for a non-randomised study with regard to this domain but cannot be considered comparable to a well-performed randomised trial.

Unclear risk of bias: too few details are available to make a judgement of 'critical', 'serious', 'moderate', or 'low' risk

Table 8. Risk of bias - Lockley 2014

\begin{tabular}{lll}
\hline Domain & $\begin{array}{l}\text { Authors' judge- } \\
\text { ment }\end{array}$ & Support for judgement \\
\hline Bias due to confounding & Moderate risk & $\begin{array}{l}\text { The study did not take into account the possibility of potential confounding ef- } \\
\text { fects as a result of media publicity which could have promoted the jump site }\end{array}$ \\
\hline $\begin{array}{l}\text { Bias in selection of partici- } \\
\text { pants/data }\end{array}$ & Low risk & $\begin{array}{l}\text { The study assessed interventions that were aimed at the general population, } \\
\text { therefore all individuals who would have been eligible to take part in the study } \\
\text { were included }\end{array}$
\end{tabular}


Table 8. Risk of bias - Lockley 2014 (Continued)

\begin{tabular}{lll}
$\begin{array}{l}\text { Bias in classification of inter- } \\
\text { ventions }\end{array}$ & Low risk & Intervention status is well defined \\
\hline $\begin{array}{l}\text { Bias due to deviations from } \\
\text { intended interventions }\end{array}$ & Low risk & $\begin{array}{l}\text { There were no deviations from the intended interventions that were likely to } \\
\text { impact on the outcome }\end{array}$ \\
\hline Bias due to missing data & Moderate risk & Some of the quantitative data sets were limited \\
\hline $\begin{array}{l}\text { Bias in measurement of out- } \\
\text { comes }\end{array}$ & Low risk & $\begin{array}{l}\text { The methods of outcome assessment were comparable across intervention } \\
\text { periods }\end{array}$ \\
\hline $\begin{array}{l}\text { Bias in selection of reported } \\
\text { result }\end{array}$ & Unclear risk & $\begin{array}{l}\text { No access to study protocols for this study therefore it is difficult to assess this } \\
\text { domain }\end{array}$ \\
\hline
\end{tabular}

Low risk of bias: the study is comparable to a well-performed randomised trial with regard to this domain.

Moderate risk of bias: the study is sound for a non-randomised study with regard to this domain but cannot be considered comparable to a well-performed randomised trial.

Unclear risk of bias: too few details are available to make a judgement of 'critical', 'serious', 'moderate', or 'low' risk

Table 9. Risk of bias - Mohl 2012

\begin{tabular}{|c|c|c|}
\hline Domain & $\begin{array}{l}\text { Authors' judge- } \\
\text { ment }\end{array}$ & Support for judgement \\
\hline Bias due to confounding & Moderate risk & $\begin{array}{l}\text { The study did not take into account the possibility of potential confounding } \\
\text { effects as a result of media publicity which could have promoted the jump } \\
\text { site }\end{array}$ \\
\hline $\begin{array}{l}\text { Bias in selection of partici- } \\
\text { pants/data }\end{array}$ & Low risk & $\begin{array}{l}\text { The study assessed interventions that were aimed at the general popula- } \\
\text { tion, therefore all individuals who would have been eligible to take part in the } \\
\text { study were included }\end{array}$ \\
\hline $\begin{array}{l}\text { Bias in classification of inter- } \\
\text { ventions }\end{array}$ & Low risk & Intervention status is well defined \\
\hline $\begin{array}{l}\text { Bias due to deviations from in- } \\
\text { tended interventions }\end{array}$ & Low risk & $\begin{array}{l}\text { There were no deviations from the intended interventions that were likely to } \\
\text { impact on the outcome }\end{array}$ \\
\hline Bias due to missing data & Low risk & Data were reasonably complete \\
\hline $\begin{array}{l}\text { Bias in measurement of out- } \\
\text { comes }\end{array}$ & Low risk & $\begin{array}{l}\text { The methods of outcome assessment were comparable across intervention } \\
\text { periods }\end{array}$ \\
\hline $\begin{array}{l}\text { Bias in selection of reported } \\
\text { result }\end{array}$ & Unclear risk & $\begin{array}{l}\text { No access to study protocols for this study therefore it is difficult to assess } \\
\text { this domain }\end{array}$ \\
\hline
\end{tabular}

Low risk of bias: the study is comparable to a well-performed randomised trial with regard to this domain.

Moderate risk of bias: the study is sound for a non-randomised study with regard to this domain but cannot be considered comparable to a well-performed randomised trial.

Unclear risk of bias: too few details are available to make a judgement of 'critical', 'serious', 'moderate', or 'low' risk

Table 10. Risk of bias - Pelletier 2007

\begin{tabular}{ll}
\hline Domain & $\begin{array}{l}\text { Authors' judge- Support for judgement } \\
\text { ment }\end{array}$
\end{tabular}


Table 10. Risk of bias - Pelletier 2007 (Continued)

\begin{tabular}{|c|c|c|}
\hline $\begin{array}{l}\text { Bias due to con- } \\
\text { founding }\end{array}$ & Moderate risk & $\begin{array}{l}\text { The study did not take into account the possibility of potential confounding effects as a } \\
\text { result of media publicity which could have promoted the jump site }\end{array}$ \\
\hline
\end{tabular}

\begin{tabular}{|c|c|c|}
\hline $\begin{array}{l}\text { Bias in selection of } \\
\text { participants/data }\end{array}$ & Low risk & $\begin{array}{l}\text { The study assessed interventions that were aimed at the general population, therefore } \\
\text { all individuals who would have been eligible to take part in the study were included }\end{array}$ \\
\hline
\end{tabular}

\begin{tabular}{|c|c|c|}
\hline $\begin{array}{l}\text { Bias in classification } \\
\text { of interventions }\end{array}$ & Moderate risk & $\begin{array}{l}\text { The authors stated that electronic death records between } 1960 \text { and } 1974 \text { did not meet } \\
\text { current data quality standards, leading to a potential underestimation of suicides dur- } \\
\text { ing this period of time. We judged that if issues with data acquisition led to a poten- } \\
\text { tial underestimation of suicides during the time period, then it would most likely have } \\
\text { been problems with classification or suicide ascertainment }\end{array}$ \\
\hline
\end{tabular}

\begin{tabular}{lll}
\hline $\begin{array}{l}\text { Bias due to devia- } \\
\text { tions from intended } \\
\text { interventions }\end{array}$ & Low risk & $\begin{array}{l}\text { There were no deviations from the intended interventions that were likely to impact on } \\
\text { the outcome }\end{array}$ \\
\hline $\begin{array}{l}\text { Bias due to missing } \\
\text { data }\end{array}$ & Moderate risk & Data from 1968 were not available \\
\hline $\begin{array}{l}\text { Bias in measurement } \\
\text { of outcomes }\end{array}$ & Low risk & The methods of outcome assessment were comparable across intervention periods \\
\hline $\begin{array}{l}\text { Bias in selection of } \\
\text { reported result }\end{array}$ & Unclear risk & No access to study protocols for this study therefore it is difficult to assess this domain \\
\hline
\end{tabular}

Low risk of bias: the study is comparable to a well-performed randomised trial with regard to this domain.

Moderate risk of bias: the study is sound for a non-randomised study with regard to this domain but cannot be considered comparable to a well-performed randomised trial.

Unclear risk of bias: too few details are available to make a judgement of 'critical', 'serious', 'moderate', or 'low' risk

Table 11. Risk of bias - Perron 2013

\begin{tabular}{|c|c|c|}
\hline Domain & $\begin{array}{l}\text { Authors' judge- } \\
\text { ment }\end{array}$ & Support for judgement \\
\hline Bias due to confounding & Moderate risk & $\begin{array}{l}\text { The study did not take into account the possibility of potential confounding ef- } \\
\text { fects as a result of media publicity which could have promoted the jump site }\end{array}$ \\
\hline $\begin{array}{l}\text { Bias in selection of partici- } \\
\text { pants/data }\end{array}$ & Low risk & $\begin{array}{l}\text { The study assessed interventions that were aimed at the general population, } \\
\text { therefore all individuals who would have been eligible to take part in the study } \\
\text { were included }\end{array}$ \\
\hline $\begin{array}{l}\text { Bias in classification of in- } \\
\text { terventions }\end{array}$ & Low risk & Intervention status is well defined \\
\hline $\begin{array}{l}\text { Bias due to deviations from } \\
\text { intended interventions }\end{array}$ & Low risk & $\begin{array}{l}\text { There were no deviations from the intended interventions that were likely to im- } \\
\text { pact on the outcome }\end{array}$ \\
\hline Bias due to missing data & Moderate risk & $\begin{array}{l}\text { Suicides occurring between July } 12004 \text { and December } 312004 \text { were excluded } \\
\text { from analysis }\end{array}$ \\
\hline $\begin{array}{l}\text { Bias in measurement of out- } \\
\text { comes }\end{array}$ & Low risk & $\begin{array}{l}\text { The methods of outcome assessment were comparable across intervention pe- } \\
\text { riods }\end{array}$ \\
\hline $\begin{array}{l}\text { Bias in selection of reported } \\
\text { result }\end{array}$ & Unclear risk & $\begin{array}{l}\text { No access to study protocols for this study therefore it is difficult to assess this } \\
\text { domain }\end{array}$ \\
\hline
\end{tabular}


Low risk of bias: the study is comparable to a well-performed randomised trial with regard to this domain.

Moderate risk of bias: the study is sound for a non-randomised study with regard to this domain but cannot be considered comparable to a well-performed randomised trial.

Unclear risk of bias: too few details are available to make a judgement of 'critical', 'serious', 'moderate', or 'low' risk

Table 12. Risk of bias - Reisch 2005

\begin{tabular}{|c|c|c|}
\hline Domain & $\begin{array}{l}\text { Authors' judge- } \\
\text { ment }\end{array}$ & Support for judgement \\
\hline Bias due to confounding & Moderate risk & $\begin{array}{l}\text { The study did not take into account the possibility of potential confounding } \\
\text { effects as a result of media publicity which could have promoted the jump } \\
\text { site }\end{array}$ \\
\hline $\begin{array}{l}\text { Bias in selection of partici- } \\
\text { pants/data }\end{array}$ & Low risk & $\begin{array}{l}\text { The study assessed interventions that were aimed at the general popula- } \\
\text { tion, therefore all individuals who would have been eligible to take part in the } \\
\text { study were included }\end{array}$ \\
\hline $\begin{array}{l}\text { Bias in classification of inter- } \\
\text { ventions }\end{array}$ & Low risk & Intervention status is well defined \\
\hline $\begin{array}{l}\text { Bias due to deviations from in- } \\
\text { tended interventions }\end{array}$ & Low risk & $\begin{array}{l}\text { There were no deviations from the intended interventions that were likely to } \\
\text { impact on the outcome }\end{array}$ \\
\hline Bias due to missing data & Low risk & Data were reasonably complete \\
\hline $\begin{array}{l}\text { Bias in measurement of out- } \\
\text { comes }\end{array}$ & Low risk & $\begin{array}{l}\text { The methods of outcome assessment were comparable across intervention } \\
\text { periods }\end{array}$ \\
\hline $\begin{array}{l}\text { Bias in selection of reported } \\
\text { result }\end{array}$ & Unclear risk & $\begin{array}{l}\text { No access to study protocols for this study therefore it is difficult to assess } \\
\text { this domain }\end{array}$ \\
\hline
\end{tabular}

Low risk of bias: the study is comparable to a well-performed randomised trial with regard to this domain.

Moderate risk of bias: the study is sound for a non-randomised study with regard to this domain but cannot be considered comparable to a well-performed randomised trial.

Unclear risk of bias: too few details are available to make a judgement of 'critical', 'serious', 'moderate', or 'low' risk

Table 13. Risk of bias - Sinyor 2010/Sinyor 2017

\begin{tabular}{|c|c|c|}
\hline Domain & $\begin{array}{l}\text { Authors' judge- } \\
\text { ment }\end{array}$ & Support for judgement \\
\hline Bias due to confounding & Low risk & The study took into account all potential confounding effects \\
\hline $\begin{array}{l}\text { Bias in selection of partici- } \\
\text { pants/data }\end{array}$ & Low risk & $\begin{array}{l}\text { The study assessed interventions that were aimed at the general popula- } \\
\text { tion, therefore all individuals who would have been eligible to take part in } \\
\text { the study were included }\end{array}$ \\
\hline $\begin{array}{l}\text { Bias in classification of interven- } \\
\text { tions }\end{array}$ & Low risk & Intervention status is well defined \\
\hline $\begin{array}{l}\text { Bias due to deviations from in- } \\
\text { tended interventions }\end{array}$ & Low risk & $\begin{array}{l}\text { There were no deviations from the intended interventions that were likely } \\
\text { to impact on the outcome }\end{array}$ \\
\hline Bias due to missing data & Low risk & Data were reasonably complete \\
\hline
\end{tabular}


Table 13. Risk of bias - Sinyor 2010/Sinyor 2017 (Continued)

\begin{tabular}{lll}
$\begin{array}{l}\text { Bias in measurement of out- } \\
\text { comes }\end{array}$ & Low risk & $\begin{array}{l}\text { The methods of outcome assessment were comparable across interven- } \\
\text { tion periods }\end{array}$ \\
\hline $\begin{array}{l}\text { Bias in selection of reported re- } \\
\text { sult }\end{array}$ & Unclear risk & $\begin{array}{l}\text { No access to study protocols for this study therefore it is difficult to assess } \\
\text { this domain }\end{array}$ \\
\hline
\end{tabular}

Low risk of bias: the study is comparable to a well-performed randomised trial with regard to this domain.

Moderate risk of bias: the study is sound for a non-randomised study with regard to this domain but cannot be considered comparable to a well-performed randomised trial.

Unclear risk of bias: too few details are available to make a judgement of 'critical', 'serious', 'moderate', or 'low' risk

Table 14. Risk of bias - Skegg 2009

\begin{tabular}{|c|c|c|}
\hline Domain & $\begin{array}{l}\text { Authors' judge- } \\
\text { ment }\end{array}$ & Support for judgement \\
\hline Bias due to confounding & Moderate risk & $\begin{array}{l}\text { The study did not take into account the possibility of potential confounding } \\
\text { effects as a result of media publicity which could have promoted the jump } \\
\text { site }\end{array}$ \\
\hline $\begin{array}{l}\text { Bias in selection of partici- } \\
\text { pants/data }\end{array}$ & Low risk & $\begin{array}{l}\text { The study assessed interventions that were aimed at the general popula- } \\
\text { tion, therefore all individuals who would have been eligible to take part in the } \\
\text { study were included }\end{array}$ \\
\hline $\begin{array}{l}\text { Bias in classification of inter- } \\
\text { ventions }\end{array}$ & Low risk & Intervention status is well defined \\
\hline $\begin{array}{l}\text { Bias due to deviations from in- } \\
\text { tended interventions }\end{array}$ & Low risk & $\begin{array}{l}\text { There were no deviations from the intended interventions that were likely to } \\
\text { impact on the outcome }\end{array}$ \\
\hline Bias due to missing data & Low risk & Data were reasonably complete \\
\hline $\begin{array}{l}\text { Bias in measurement of out- } \\
\text { comes }\end{array}$ & Low risk & $\begin{array}{l}\text { The methods of outcome assessment were comparable across intervention } \\
\text { periods }\end{array}$ \\
\hline $\begin{array}{l}\text { Bias in selection of reported } \\
\text { result }\end{array}$ & Unclear risk & $\begin{array}{l}\text { No access to study protocols for this study therefore it is difficult to assess } \\
\text { this domain }\end{array}$ \\
\hline
\end{tabular}

Low risk of bias: the study is comparable to a well-performed randomised trial with regard to this domain.

Moderate risk of bias: the study is sound for a non-randomised study with regard to this domain but cannot be considered comparable to a well-performed randomised trial.

Unclear risk of bias: too few details are available to make a judgement of 'critical', 'serious', 'moderate', or 'low' risk

Table 15. Quality assessment - Whitmer 2013

\begin{tabular}{ll}
\hline Domain & Authors' judgement \\
\hline Study design & Yes \\
\hline Selection of alternatives & No \\
\hline Form of evaluation & Yes \\
\hline Effectiveness data & Not clear \\
\hline
\end{tabular}


Table 15. Quality assessment - Whitmer 2013 (Continued)

Benefit measurement and valuation

Yes

\begin{tabular}{ll}
\hline Costing & Yes \\
\hline Modelling & Not clear \\
\hline Adjustments for timing of costs and benefits & Yes \\
\hline Allowance for uncertainty & Not clear \\
\hline Presentation of results & Yes \\
\hline
\end{tabular}

\section{AP PEN DICES}

\section{Appendix 1. Ovid MEDLINE, EMBASE, PsycINFO search strategies}

Ovid MEDLINE(R) and Epub Ahead of Print, In-Process \& Other Non-Indexed Citations and Daily <1946 onwards $>$, Ovid Embase <1974 onwards>, Ovid PsycINFO <1806 onwards>

Date of Search: 31 May 2019

[Setting]

1. hotspot\$.mp.

2. (cliff\$ or roof\$ or building\$ or high-rise or multistorey or viaduct\$ or magnet\$ or bridge\$ or flyover $\$$ or overpass or skyscraper\$ or car park\$).mp.

3. (bridge $\$$ adj3 (motorway\$ or highway\$ or reservoir\$ or coast\$ or road\$)).mp.

4. (jump* or leap* or fall* or height).mp.

[Intervention]

5. (fenc ${ }^{\star}$ or barrier ${ }^{\star}$ or parapet or net ${ }^{\star}$ or sign ${ }^{\star}$ or poster $^{\star}$ or surveillance $^{\star}$ or CCTV or patrol $\left.{ }^{\star}\right)$.mp.

6. means restriction. $\mathrm{mp}$.

7. exp *Risk Reduction Behavior/

8. ((limit ${ }^{\star}$ or restrict $\left.^{\star}\right)$ adj3 (access ${ }^{\star}$ or mean ${ }^{\star} 1$ or method $\left.\left.^{\star} 1\right)\right) \cdot \mathrm{mp}$.

9. exp *Environment Design/

10. exp *Crisis Intervention/

11. exp *Architectural Accessibility/

12. exp *Safety Management/

13. ((prevent ${ }^{\star}$ and suicid $\left.{ }^{\star}\right)$ or ((preventive or prevention) and (intervention* or program $\left.\left.{ }^{\star}\right)\right)$ or (prevention and control)).mp.

[Population]

14. exp *Suicide/ or exp Suicide, Attempted/

15. exp *Self-Injurious Behavior/

16. 1 or 2 or 3 or 4

17.5 or 6 or 7 or 8 or 9 or 10 or 11 or 12 or 13 
18. 14 or 15

19. 16 and 17 and 18

[mp=title, abstract, original title, name of substance word, subject heading word, floating sub-heading word, keyword heading word, organism supplementary concept word, protocol supplementary concept word, rare disease supplementary concept word, unique identifier, synonyms]

\section{Appendix 2. Web of Science search strategy}

Web of Science Core Collection (Science Citation Database (SCI) $<1900$ onwards $>$ and Social Science Citation Database (SSCI) $<1956$ onwards)

Date of Search: 31 May 2019

\#1. TS=hotspot\$

\#2. TS=(cliff\$ OR roof\$ OR building\$ OR high-rise OR multistorey OR viaduct\$ OR magnet\$ OR bridge\$ OR flyover\$ OR overpass OR skyscraper\$ OR car park\$)

\#3. TS=(jump* OR leap* OR fall* OR height)

\#4. TS=(fenc ${ }^{\star}$ OR barrier ${ }^{\star}$ OR parapet OR net ${ }^{\star}$ OR sign ${ }^{\star}$ OR poster ${ }^{\star}$ OR surveillance ${ }^{\star}$ OR CCTV or patrol $\left.{ }^{\star}\right)$

\#5. TS=means restriction

\#6. TS=risk reduction

\#7. TS=(limit ${ }^{\star}$ OR restrict $\left.{ }^{\star}\right)$

\#8. TS=(environment design OR crisis intervention OR architectural accessibility OR safety management)

\#9. TS=((prevent* AND suicid $\left.{ }^{\star}\right)$ OR ((preventive OR prevention) AND (intervention* OR program)) OR (prevention and control))

\#10. TS=(suicide OR parasuicide OR attempted suicide OR self harm OR self injurious behavior*)

\#11. \#3 OR \#2 OR \#1

\#12. \#9 OR \#8 OR \#7 OR \#6 OR \#5 OR \#4

\#13. \#12 AND \#11 AND \#10

Appendix 3. CENTRAL search strategy

Cochrane Central Register of Controlled Trials (CENTRAL) Issue 5 of 12, May 2019

$\# 1$ hotspot $\$$ or cliff\$ or roof\$ or building\$ or high-rise or multistorey or viaduct\$ or magnet\$ or bridge or flyover $\$$ or overpass or skyscraper $\$$ or car park\$

\#2 bridge adj3 (motorway\$ or highway\$ or reservoir\$ or coast\$ or road\$)

$\# 3$ jump* or leap* or fall* or height

\#4 fenc ${ }^{\star}$ or barrier ${ }^{\star}$ or parapet or net ${ }^{\star}$ or sign ${ }^{\star}$ or poster ${ }^{\star}$ or surveillance* or CCTV or patrol $^{\star}$

\#5 means restriction

\#6 risk reduction

\#7 ((limit ${ }^{\star}$ or restrict $\left.{ }^{\star}\right)$ adj3 (access ${ }^{\star}$ or mean ${ }^{\star} 1$ or method $\left.^{\star} 1\right)$ )

\#8 Environment Design or Crisis Intervention or Architectural Accessibility or Safety Management

\#9 ((prevent ${ }^{\star}$ and suicid $\left.{ }^{\star}\right)$ or ((preventive or prevention) and (intervention* or program $\left.\left.{ }^{\star}\right)\right)$ or (prevention and control))

\#10 MeSH descriptor: [Suicide] explode all trees

\#11 MeSH descriptor: [Self-Injurious Behavior] this term only

$\# 12 \# 1$ or \#2 or \#3

$\# 13 \# 4$ or \#5 or \#6 or \#7 or \#8 or \#9

$\# 14 \# 10$ or \#11

$\# 15$ \#12 and \#13 and \#14

\section{CONTRIBUTIONSOF AUTHORS}

Conceiving the concept of the review: AJ

Developing the basis for the protocol: AJ, MD, SP, KL 
Writing the protocol: $\mathrm{AJ}, \mathrm{CO}$

Searching for studies: CO

Selecting studies: CO, UK, AJ

Extracting data from studies: CO, UK, SW, AJ

Entering data into RevMan: CO

Analysing data: AG, CO

Interpreting the analysis: AG, CO

Drafting and revising manuscript: all review authors

\section{DECLARATIONS OF INTEREST}

$\mathrm{KL}$ and AJ are co-directors of the Cochrane Satellite for Suicide and Self-Harm portion of the Cochrane Common Mental Disorders Group; $\mathrm{SP}$ and $\mathrm{CO}$ are members.

$\mathrm{KH}$ has been involved in trials and studies related to means restriction of paracetamol/aspirin and locked boxes in low- and middle-income countries, and played no part in any decisions related to any of his studies.

MD: none

UK: none

SW: none

AG: none

\section{SOURCES OF SUPPORT}

\section{Internal sources}

- Swansea University, UK.

\section{External sources}

- Public Health Wales, UK.

\section{DIFFERENCES BETWEEN PROTOCOLANDREVIEW}

None 